WORKING PAPERS

\title{
Issues in Estimating Benefits with Non-Market Methods
}

\author{
Kenneth E. McConnell ${ }^{1}$ \\ Department of Agricultural and Resource Economics \\ University of Maryland
}

Working Paper Series 308

Washington, D.C.

\footnotetext{
${ }^{1}$ This report was prepared when Mr. McConnell was a consultant with the Office of the Chief Economist (OCE), Inter-American Development Bank. William D. Savedoff, OCE, and William J. Vaughan, Social Programs and Sustainable Development Department, both with the Inter-American Development Bank, Provided many helpful comments.
} 


\section{INTRODUCTION}

This paper concerns the estimation of benefits used in the evaluation of development projects, especially public facilities or environmental projects. The estimation of benefits uses a variety of techniques, both contingent valuation and behavioral techniques. Benefit measures presumably have an important role in the allocation of funds for development banks. The consequence of inappropriate project analysis is that lending will increase debt burdens without corresponding economic and social benefits. The paper reviews methods for evaluating projects, especially projects with multiple design options.

Traditionally, measures of benefits have been used in project analysis. But there is room for other uses of non-market valuation techniques. Interest in GNP accounts augmented with environmental effects requires tracking the value of natural resources as assets. While the focus of such studies has been on declines in productivity from degradable or exhaustible resources, nonmarket resources may be a more important omission from the accounts than resources which are marketed but insufficiently protected by entrepreneurs. Augmenting GNP accounts should rest on a solid base of non-market valuation. Attempts to include non-market values can reveal some of the pitfalls of green accounting.

The contribution of resource values to the debate about policy and legislation is a more compelling reason for building the intellectual basis for non-market valuation. Economic analysis can help create a culture which recognizes trade-offs when development banks engages in policy dialogues with their members. Part of this analysis entails recognizing and accounting for the value of goods and services not sold on the market.

This paper reviews the estimation of benefits for project analysis, especially with regard to quality changes and multiple quality changes. The emphasis is on intuitive results and empirical applications. There is a fairly full set of references to the literature. ${ }^{1}$ These references include extensions of models in ways that could prove useful in project analysis. Standard references to the material in this paper include the book by Freeman (1993), and the books edited by Braden and Kolstad and by Kopp and Smith.

\section{BENEFIT MEASURES FOR QUALITY CHANGES.}

This section renders an intuitive framework for valuing the kinds of quality changes that are experienced in many project designs. Many projects have multiple design options or service 
flows with several characteristics. For example, planning of the construction of waste water treatment facilities might have the following benefits:

- removal of waste water via major trunk line to a river,

- removal and primary treatment, or

- removal and secondary treatment.

The three options might represent three increments of improved water quality over the current situation. For example, the most basic improvement in water quality could make a river aesthetically more appealing by removing debris and reducing odor. Additional stages would improve the river to fishable and then to swimmable. Another frequent kind of development project provides sewer hookups as well as drainage. Household sewage removal and protection from flooding are the two services offered by such projects and they are only generally related in the household's preference function. In some situations, several alternatives are proposed, with each alternative having a different group of attributes embodied in it. For example, in the study "Investigacion de Disposicion a Pagar por Soluciones de Vivienda Progresiva", prepared by Research Chile, each of the four housing alternatives considered has a different bundle of attributes. The common element in all of these projects is the provision of several services or the improvement in the quality of a given service. Rarely do these projects provide a simple increase in a single commodity at a given price or a simple price increase, projects for which there are standard and well understood welfare measures.

The economic aspects of this type of planning involve the measurement of the economic value of (or willingness to pay for) the improved qualities, or simultaneous changes in quality and quantity over the current situation. Hence it is useful to describe in concept what we want to measure and to use the concepts in setting up econometric models. A simple definition of benefits and how they are measured is especially warranted for quality changes, where the intuitive appeal to the area under demand curves is lacking. This section describes conceptual measures and provides literature citations which would allow the reader to pursue the issue in greater depth. A broad introduction and useful reference is the book by Freeman (1993).

The distinction between variables which are endogenous to households and those which are exogenous to the household but are under the control of public agencies is important for project analysis. Public goods such as outdoor air quality are typically exogenous to individuals but subject to social control. Similarly, paved streets are public goods, conditioned on the household living near the street. Households can choose paved streets only by choosing a particular housing 
bundle. For ease of modeling and probably for a better understanding of how decisions are made, both by households and agencies, assume that projects change variables which are exogenous to households, and that benefit measures are derived as a consequence of these exogenous effects. For example, in the case of sewage treatment plants, the treatment of the water provides a safer environment (perhaps cleaner water for swimming) and households respond by going swimming more frequently, indicating improved welfare. Paving a street changes the bundle of characteristics that adheres to a group of houses, and the goal of welfare measurement is to infer the benefits of the improved characteristics from household responses to survey questions or evidence from past household rental or purchase behavior. This differs from the evaluation of many kinds of public policies which seek to determine the price or quantity of a commodity sold on the market, such as frequently occurs in agricultural policy. The assumption that projects provide services which are given exogenously to households is a reasonable modeling approach in the sense that it captures the spirit of many projects and permits a transparent story about benefit calculation.

Benefit estimation begins with the specification of a preference function of a household, rather than an individual The household will be the unit of analysis in this paper, because it is generally the principal decision-making unit, and household surveys are the rule rather than the exception, whether the survey is in home or, less likely, by phone. But the same preference function will lead to rather different methods of welfare measurement, depending on the degree to which market prices are influenced by outcomes. When market prices are influenced by the quality of the good provided, the hedonic model is relevant. When behavior is changed by the quality of the good, the project or the public action, but prices are not, then the researcher must turn to contingent valuation methods or behavioral methods such as travel cost models or random utility models for results. And when the quality of the good, the project or the public action changes individual welfare, but without behavioral traces, then the researcher is limited to contingent valuation methods.

\section{IIA. When Quality Changes but Prices Are Constant.}

Suppose the household has preferences defined by the direct utility function $\mathrm{U}(\mathrm{x}, \mathrm{z}, \mathrm{q})$ where $\mathrm{x}$ is a vector of private goods, $\mathrm{q}$ is a vector of the characteristics of the private goods, and $\mathrm{z}$ is a Hicksian bundle, that is, a place to spend income that is not spent on $\mathrm{x}$. The vector q describes the quality of each of the $x$ 's. For example, $x_{1}$ might be the quantity of drinking water from a particular source and $\mathrm{q}_{11}$ the reading of pathogens per cubic liter of this drinking water while $\mathrm{q}_{12}$ might be the suspended solids per liter. Further, $\mathrm{x}_{2}$ could be trips to a particular body of water for 
recreational purposes, $\mathrm{q}_{21}$ a measure of the quality of the water, such as the fecal coliform count and $\mathrm{q}_{22}$ another measure of quality, such as the dissolved oxygen (DO).

In practice, several measures of quality frequently change at the same time, or at least several are involved in the change. For example, a typical contingent valuation scenario for water quality might describe it as swimmable at one level of policy and not swimmable at another level. This could be described scientifically in terms of the q's which determine water quality, such as dissolved oxygen or heavy metal concentration or fecal coliform count. But instead of changing the whole bundle of q's, we would simply create a discrete q which would take the value of 1 if the water were drinkable and 0 otherwise. The theory would operate the same on this discrete change as it would on the change in a bundle of q's.

To balance the budget, let $\mathrm{p}$ be the vector of prices of the $\mathrm{x}$ vector, let the price of the Hicksian bundle be one, and let income be $\mathrm{y}$. Then the budget constraint will be $\mathrm{px}+\mathrm{z}=\mathrm{y}$. Sometimes it will be useful to have $\mathrm{x}$ only one dimension. No conclusions depend on the number of dimensions of $\mathrm{x}$, only convenience. With the budget constraint, we can define the functions which lead to welfare measures.

The indirect utility function is $\mathrm{V}(\mathrm{p}, \mathrm{q}, \mathrm{y})$ is a measure of utility as a function of prices, qualities, and income derived from maximizing utility subject to the budget constraint. It describes the level of utility that a household achieves when choices are made, as a function of the determinants of choice. It is indirect because utility depends on consumption choices, which depend on these determinants (prices, characteristics of goods, income, and many other variables which could be in the indirect utility function) rather than the consumed goods themselves.

For each commodity there is a choke price, $\mathrm{p}^{*}$. It is a price so high that the household would not purchase the marketed good. The choke price will depend on many things, including household income, the quality of the good, and substitutes. For example for most people, the choke price of a Coke from a soda machine which also provides Pepsi would probably be just a few cents higher than the price for Pepsi.

For a particular good $\mathrm{x}$, the Marshallian demand is given by

$$
\mathrm{x}_{\mathrm{i}}=\mathrm{f}_{\mathrm{i}}(\mathrm{p}, \mathrm{q}, \mathrm{y}) \text {. }
$$

A demand curve is Marshallian when it depends on income and prices, and differs from the Hicksian or utility-constant demand curve. Marshallian demand curves correspond to observed behavior. 
The goal is to state in theory how one would measure the benefits of a project. Typically, the project provides a new commodity which differs in attributes from the existing commodities, although it may be a close substitute to a service currently available. The benefits can be described as the change in welfare from the initial state, where the price of the commodity is $\mathrm{p}^{*}$ without the project to the welfare in the final state, where the price of the new commodity is $p^{0}$ with the project. The benefits of providing the new commodity are

$$
\mathrm{V}\left(\mathrm{p}^{*}, \mathrm{q}, \mathrm{y}-\mathrm{cv}_{\mathrm{a}}\right)=\mathrm{V}\left(\mathrm{p}^{0}, \mathrm{q}, \mathrm{y}\right)
$$

where the welfare measure is $\mathrm{cv}_{\mathrm{a}}$, the compensating variation for access to the good or service. Here $\mathrm{cv}_{\mathrm{a}}$ is just the amount of money that makes the household indifferent between being able to consume $\mathrm{x}$ at a price of $\mathrm{p}^{0}$ and not consume $\mathrm{x}$. It may be that the new $\mathrm{x}$ is just a slightly different form of a commodity or service currently available, such as water which has been treated for pathogens, rather than untreated water.

In most cases, this welfare measure could be calculated simply as the area under a demand curve, i.e.:

$$
\mathrm{cs}_{\mathrm{a}}=\int_{\mathrm{p} 0}^{\mathrm{p}^{*}} \mathrm{f}(\mathrm{p}, \mathrm{q}, \mathrm{y}) \mathrm{dp}
$$

where $\mathrm{cs}_{\mathrm{a}}$ is the consumer surplus and the subscript $a$ stands for access. Equation (3) is the standard area under the Marshallian demand curve. It is the maximum amount a household would pay for the right to consume $\mathrm{x}$ at a price of $\mathrm{p}^{0}$ with quality $\mathrm{q}$. This is typically what we mean when writing about consumer surplus. However, in contingent valuation work, researchers usually try to formulate questions to induce a response of $\mathrm{cv}_{\mathrm{a}}$, as in eq. (2). When the income effect is small or the commodity unimportant in terms of its budget share, compensating and equivalent variation and consumer surplus are all close, and $\mathrm{cs}_{\mathrm{a}}$ and $\mathrm{cv}_{\mathrm{a}}$ are equal. That is equivalent to saying that (2) and (3) yield the same number. In practice, measurement errors may be more important than income effects. Hence terms such as consumer surplus, willingness to sell and willingness to pay can be used interchangeably. For expenditures which are a large share of household budgets, however, this is not true. When households pay significant proportions of their money income for a good, then consumer surplus will differ from the more exact measures--compensating and equivalent variation. Care must be taken therefore with commodities such as housing or sanitation in very poor areas.

Frequently the project analysis will deal with improvements of quality, say water quality. Then the benefit measure is 


$$
\mathrm{V}\left(\mathrm{p}, \mathrm{q}^{*}, \mathrm{y}-\mathrm{cv}_{\mathrm{q}}\right)=\mathrm{V}\left(\mathrm{p}, \mathrm{q}^{0}, \mathrm{y}\right)
$$

This is a mathematical statement of the verbal expression: find the amount of money that makes household indifferent between the original quality $\left(\mathrm{q}^{0}\right)$ and the improved quality $\left(\mathrm{q}^{*}\right)$. Here $\mathrm{cv}_{\mathrm{q}}$ is the amount of income that would make the household indifferent between the situation with less income but higher quality and the situation with original income and unimproved quality. This welfare measure has a simple and easy to calculate behavioral alternative, but only under the assumption of weak complementarity. Weak complementarity means that $\mathrm{q}$ is linked to a particular commodity and if that commodity is not consumed, the household is indifferent to changes in $\mathrm{q}$. For example, if $\mathrm{x}$ is drinking water from a particular source and $\mathrm{q}$ is suspended solids per liter of drinking water, then weak complementarity means that the household is indifferent to $\mathrm{q}$ when $\mathrm{x}$ is zero or when the price of $\mathrm{x}$ is at its choke value $\left(\mathrm{p}^{*}\right){ }^{2}$ An equivalent statement of weak complementarity is that the household will pay nothing for changes in the quality of the water from the source if it does not drink the water. (For references on weak complementarity, see Maler or Freeman, chapter 4.) Under weak complementarity between $\mathrm{x}$ and $\mathrm{q}$, an approximate welfare measure for a change in $\mathrm{q}$ is simply the change in the area under the demand curve for $\mathrm{x}$ as a consequence of the change in $\mathrm{q}$ :

$$
\mathrm{cs}_{\mathrm{q}}=\int_{\mathrm{p}^{0}}^{\mathrm{p}^{*}} \mathrm{f}\left(\mathrm{p}, \mathrm{q}^{*}, \mathrm{y}\right) \mathrm{dp}-\int_{\mathrm{p}^{0}}^{\mathrm{p}^{*}} \mathrm{f}\left(\mathrm{p}, \mathrm{q}^{0}, \mathrm{y}\right) \mathrm{dp}
$$

For practical purposes, this is the change in the area under the Marshallian demand curve for $\mathrm{x}$, shown in Figure 1 as the shaded area. It is a reasonable approximation when income effects are small. If $\mathrm{q}$ is weakly complementary to two goods, as it might be for example when a household enjoys swimming and boating at a bay considered as two separate x's, there is an analogous expression. (See Bockstael and McConnell for details.)

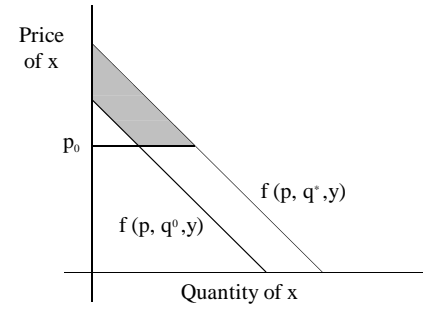

Figure 1.

For changes in the quality or characteristics of commodities the difference between compensating or equivalent variation, i.e., the exact measures and consumer surplus depends on the 
budget share and the income elasticity of the commodity, just as for the value of access. When expenditures on commodities or services are a significant proportion of the budget, as they would be for poor households, this approximation becomes less reliable.

For many problems, not only may weak complementarity fail, but in fact nonusers may value the change in quality even if they don't consume the good. Then expression (4) is still valid, but there is no good consumer surplus approximation for the full welfare measure. The welfare measure can be decomposed as follows:

$$
\mathrm{cv}_{\mathrm{q}}=\text { use value }+ \text { nonuse value, }
$$

where

$$
\text { use value }=c s_{q}
$$

and nonuse value (also called existence value) is the willingness to pay for a household which does not plan to use the resource. For a summary and guide to the literature, see Freeman, chapter 5.

Welfare measures for quality changes are simple to write in concept but in practice not so easy to calculate, especially from observations on behavior. There may be no observations on how behavior changes as quality changes, a necessary datum of this calculation. For example, if the proposed project offers an improvement in drinking water quality, the households may not have experienced the same poor quality of water for a long period of time and the improvement being investigated has not been experienced. Or perhaps the project is to prevent a decline in water quality, such as was considered in the construction of a sewage treatment plant in Barbados. This sewage treatment plant would reduce the pollutant load carried to marine waters, and hence had a potential for impact on beach use. During the time when the project was being considered, the marine water quality was quite good, but the project would prevent the deterioration of water quality. In this case, it might be possible to estimate the demand for beach going activities (such as equation (1)) but there would be no behavioral evidence on how households would respond to changes in pollutants, which would give equation (5). In such a situation, where there are no behavioral traces to exploit for the estimation of use value, contingent valuation techniques are necessary. But special care must be exercised in the use of contingent valuation when the commodity under consideration is unfamiliar. Such was the situation in Barbados, when households were asked about their willingness to pay to present a decline in water quality. In that case, research was motivated by the concern that continued population growth without sewers would degrade water quality, but there was no evidence, scientific or perceptible, that degradation had occurred or was widespread. See McConnell and Ducci. 
Nonuse value has played an increasingly important role in valuation studies in the U.S. Especially since the Exxon Valdez oil spill, researchers have approached projects with the expectation that nonuse values are worth measuring. Economists are divided on the potential magnitude of nonuse values and the ability to measure such values (see the debate between Hanemann (1994) and Diamond and Hausman and also the paper by McFadden (1994)) but there is some agreement on the idea that nonuse values are real. Growth in incomes and an expanding environmental consciousness lie behind households' averred willingness to give up income to preserve or enhance natural resources which they will never use. These forces operate at lower levels in developing countries, and so will be less of a focus in this paper. For households lacking consistently functioning waste water treatment facilities, it seems sufficient to look for the value of resources associated with basic amenities, leaving nonuse values to subsequent research. Nevertheless, when contingent valuation methods are used to estimate willingness to pay, there is no guarantee that only use values have been included.

\section{IIB. When Prices Change as a Consequence of Improved Quality.}

As long as markets and prices are not influenced by the quality of commodities or services, expressions (2) and (4) provide the framework for benefit measurement. However, some valuation tools like hedonic models utilize market price responses as a means of analysis. In hedonic markets, goods such as houses or land or cars or services such as labor have attributes which are important to buyers and sellers. Presumably, buyers maximize utility and sellers maximize profits. When the market responds to the scarcity of important attributes, prices reflect the attributes. These prices form the data for hedonic price functions which reflect only approximately the utility functions. The utility functions may also influence prices through buyers' behavior. (Except in the case where all households have identical bid functions for houses. Then the hedonic price function will simply be the household bid function. See for example, the discussion in Freeman, chapter 11, Palmquist or McConnell, 1984.) It is no longer a simple matter even in theory to go from the estimated hedonic price function, given by the market to the individual preference function. Palmquist summarizes the issues related to recovering preferences in the hedonic model.

Welfare measures and benefit calculations become more complicated with market and price responses. Welfare measurement in the hedonic framework creates three problems. First, the standard welfare measurement is much more difficult analytically, because the budget constraint is nonlinear, eliminating the easy interpretation of areas under demand curves as well as eliminating the standard Marshallian demand curve. When the marginal prices change as a 
consequence of choice, the prices-as-parameters model, the essence of duality, no longer applies. Those variables which are exogenous to the household and show up in the indirect utility function are no longer prices, but other variables which determine prices. The neat link between prices in the indirect utility function and benefits is broken. Second, hedonic analysis in practice rarely proceeds beyond the first stage of econometric analysis, so that nothing about preferences is learned. It does not proceed beyond the first stage of estimating the hedonic price function because of the identification problem. (See Epple for a study of this issue. A recent application for recovering preferences can be found in Arguea and Hsiao.) Third, when a policy or project is implemented, it has a price and quantity effect and may disturb the whole hedonic price function, not just marginal values. For example, suppose the project requires estimating the benefits of paved streets by calculating the hedonic gradient for the quality variable, paved streets. When the streets are actually paved, the effect could be large enough to cause a large change in home ownership or rentals, changing the whole hedonic price function. This issue is discussed in detail in Palmquist.

At the level of project analysis it is unreasonable to assume that the identification problem will be solved. And many projects will be small enough not to disturb the equilibrium hedonic price function. Under these assumptions, when the hedonic price function that has been estimated is $\mathrm{p}(\mathrm{q}: \gamma)$, where $\mathrm{q}$ is the bundle of attributes of the house and $\gamma$ is the vector of coefficients of the hedonic price function, the typical welfare measure is

$$
\mathrm{cs}_{\mathrm{q}}=\mathrm{p}\left(\mathrm{q}^{*} ; \gamma\right)-\mathrm{p}\left(\mathrm{q}^{0} ; \gamma\right)
$$

This welfare measure is simply the difference in the price as a consequence of the change in quality (from $\mathrm{q}^{0}$ to $\mathrm{q}^{*}$ ). This is shown in Figure 2 as the vertical distance between the original point on the hedonic function and the new point on the function. This figure shows that in equilibrium, the predicted change in the hedonic price will exceed the change in willingness to pay, which is the vertical change in the bid function from an increase in the attribute level. 


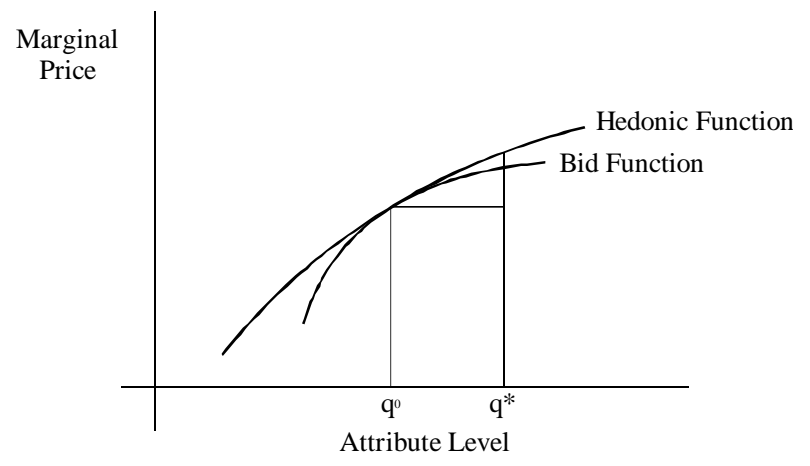

Figure 2.

The welfare measure in equation (7) does not stem directly from individual behavior, because it involves all market forces, including supply. It is indirectly related to the area under a demand curve, but cannot be directly related to such an area the way most welfare measures can. It is an approximation, but an intuitively good one, in that introspection about a single transaction can show that the housing price difference should reflect the willingness to pay for difference in attributes. Suppose that two houses are identical in all respects except that one has paved streets, and the other does not. In a well-functioning market we would expect that the buyers would bid up the price of the house with paved streets until this difference reflects only the willingness to pay for paved streets. It becomes an exact welfare measure if all households have similar preferences and income.

Kanemoto demonstrates that the predicted change in the hedonic price is an upper bound of the true willingness to pay when full adjustment in the housing market is permitted. ${ }^{3}$ Despite a great deal of discussion in the economic literature, benefit measurement for hedonic models does not typically proceed beyond (7) in practice. (There are a few exceptions. See Parsons for an example of estimating the second stage of the hedonic model. See also the paper by Arguea and Hsiao as well as Bartik, 1987) Benefits per household, $\mathrm{cs}_{\mathrm{q}}$, are just the difference in the price caused by $\mathrm{q}^{*}$ relative to $\mathrm{q}$, all else in the house equal. However, if there are other significant differences between the houses, such as houses located in two different neighborhoods, one neighborhood with paved streets and one without, the price difference will probably be systematically wrong.

An additional problem, of an econometric nature, is created by the non-linearity of the hedonic price function. In the non-linear case, the predicted price will not fit through the mean value of prices. Instead, the model will underestimate the mean if the nonlinear transformation is 
convex, and overestimate it if concave. Standard corrections are available for a simple transformation, such as the log of the dependent variable.

\section{IIC. Welfare Measures for Random Utility Models}

Two additional welfare measures are encountered occasionally: the welfare measure from the referendum model, which is typically a binary choice problem with ordered choices and the welfare measure from the random utility model, which comes from a multiple choice setting where the researcher does not know which alternative is the best. Both models ultimately use the indirect utility function of equation (4). The cases differ slightly because in the multiple choice case, the researcher does not know which of the choices would be preferred, while in the typical binary choice case of contingent valuation, the better alternative is obvious.

The simpler calculation is for the referendum model. This is the basic model for discrete choice contingent valuation. See, for example, Hanemann (1984), Cameron (1988) and McConnell. This is just an application of the basic equation (4), which uses the indirect utility function. The only difference is that the welfare per household is random to the observer. Suppose that the indirect utility functions for the alternatives can be written

$$
\mathrm{V}\left(\mathrm{p}, \mathrm{q}^{0}, \mathrm{y}\right)=\mathrm{U}\left(\mathrm{p}, \mathrm{q}^{0}, \mathrm{y}\right)+\varepsilon_{0}
$$

and

$$
\mathrm{V}\left(\mathrm{p}, \mathrm{q}^{*}, \mathrm{y}\right)=\mathrm{U}\left(\mathrm{p}, \mathrm{q}^{*}, \mathrm{y}\right)+\varepsilon_{1}
$$

where $\mathrm{V}$ is divided into deterministic components $\mathrm{U}$ and components $\varepsilon$ which are random to the observer. In this case the expression for cv still holds, but it is random. When utility is linear, as for example, $\mathrm{U}(\mathrm{p}, \mathrm{q}, \mathrm{y})=\alpha \mathrm{q}+\beta \mathrm{y}$, the expected value of $\mathrm{cv}$ is

$$
\mathrm{E}(\mathrm{cv})=\alpha\left(\mathrm{q}^{*}-\mathrm{q}^{0}\right) / \beta
$$

which is just a specific closed form solution of (4). This expression comes from the definition of $\mathrm{cv}$ as the amount of income change that makes the household indifferent to the choice. ${ }^{4}$ (This is derived in Hanemann, 1984).

The random utility model for choice among a larger set of alternatives implies a different benefit measure. In this model, the household chooses among $\mathrm{m}$ alternatives, each with a set of qualities--say $\mathrm{m}$ houses with specified number of rooms, floor area, and so forth--and a price. This model is explained in detail in Ben-Akiva and Lerman and also in Maddala. The utility from each alternative is usually written 


$$
\mathrm{v}_{\mathrm{i}}=\alpha_{\mathrm{i}}+\beta\left(\mathrm{y}-\mathrm{p}_{\mathrm{i}}\right)+\varepsilon_{\mathrm{i}}
$$

where it is useful to think of the $\alpha$ as a function of the quality variables at the site (that is, the q's are implicit in the $\alpha: \alpha=\alpha(q)$ as above, for example, $\left.\alpha=\alpha_{0}+\alpha_{1} q\right)$ and $p$ as the price of access to the site. The welfare is again measured using the analogy of (4). The household has maximum utility, but the observer can only calculate its expected value. This depends on the distribution of the error term. For $\varepsilon$ distributed extreme value, the expected maximum utility is given by: ${ }^{5}$

$$
\mathrm{V}(\mathrm{p}, \mathrm{q}, \mathrm{y})=\ln \left[\sum_{\mathrm{i}=1}^{\mathrm{m}} \exp \left(\alpha_{\mathrm{i}}+\beta\left(\mathrm{y}-\mathrm{p}_{\mathrm{i}}\right)\right)\right]+\mathrm{k} .
$$

Here $\mathrm{k}$ is a known constant (.577, from the distribution of the error) which drops out when the calculations on the differences in $\mathrm{V}$ are made.

Using the extreme value assumes the independence of irrelevant alternatives (IIA)--that is the choice between any two alternatives is independent of others. Some situations warrant the assumption of IIA, but others do not. When IIA holds, (12) can be the basis for any sort of welfare calculation which might involve, for example, the elimination of an alternative such as a beach closing down because of health warnings or a steep decline in water quality (simply drop an index from the summation) or an alteration of the $\alpha$, which might occur because of a quality change such as providing sidewalks for some houses. (This welfare measure is derived in Domencich and McFadden, 1975. See also Small and Rosen and Hanemann (1982).)

As an example, suppose that alternative one is eliminated. We can treat this as a price increase, and let $\mathrm{V}\left(\mathrm{p}^{*}, \mathrm{q}, \mathrm{y}\right)$ be the welfare level when prices have risen or alternative one is eliminated. Then using (12), we want the cv that makes $\mathrm{V}\left(\mathrm{p}^{*}, \mathrm{q}, \mathrm{y}-\mathrm{cv}\right)$ equal to $\mathrm{V}(\mathrm{p}, \mathrm{q}, \mathrm{y})$. Using (12), this implies that

$$
\ln \left[\sum_{\mathrm{i}=1}^{\mathrm{m}} \exp \left(\alpha_{\mathrm{i}}+\beta\left(\mathrm{y}-\mathrm{p}_{\mathrm{i}}\right)\right)\right]+\mathrm{k}=\ln \left[\sum_{\mathrm{i}=2}^{\mathrm{m}} \exp \left(\alpha_{\mathrm{i}}+\beta\left(\mathrm{y}-\mathrm{p}_{\mathrm{i}}-\mathrm{cv}\right)\right)\right]+\mathrm{k} .
$$

This can be solved for cv as follows: ${ }^{6}$

$$
\mathrm{cv}=\beta^{-1} \ln \left\{\left[\sum_{\mathrm{i}=1}^{\mathrm{m}} \exp \left(\alpha_{\mathrm{i}}+\beta\left(\mathrm{y}-\mathrm{p}_{\mathrm{i}}\right)\right)\right] /\left[\sum_{\mathrm{i}=2}^{\mathrm{m}} \exp \left(\alpha_{\mathrm{i}}+\beta\left(\mathrm{y}-\mathrm{p}_{\mathrm{i}}\right)\right)\right]\right\} .
$$

Welfare measures are occasionally revealing in their calculation. Suppose again that the goal is to value the elimination of the first alternative. Then the process of calculating (13) yields ${ }^{7}$

$$
\mathrm{cv}=-\ln (1-\operatorname{Prob}(1)) / \beta
$$

where Prob(1) is the probability of choosing site 1 , prior to its elimination and $\beta$ is the marginal utility of income. (A derivation of the RUM welfare measures in terms of behavioral relations 
analogous to consumer surplus can be found in McConnell (1994)). As this probability gets very small, the welfare measure goes to zero. As Prob(1) gets large, the value of access grows. If the measures pertain to elimination or introduction of an alternative, equation (14) provides a good check on the estimates.

The standard test for IIA is derived in Hausman and McFadden and can be performed easily in packages such as LIMDEP. When IIA does not hold, either because it is obvious from the construction of the problem or because such econometric tests have shown that it is violated, then the problem needs to be restructured. Allowing nesting or sequential choices typically means revising the preference function as well as the distribution of errors.

When the IIA does not hold, the nested logit may be appropriate. Consider the joint choice of neighborhood and house. Suppose that utility is given by

$$
\mathrm{V}(\mathrm{p}, \mathrm{q}, \mathrm{y})=\alpha \mathrm{q}_{\text {is }}+\gamma \mathrm{w}_{\mathrm{s}}+\beta\left(\mathrm{y}-\mathrm{p}_{\text {is }}\right)+\eta_{\text {is }}
$$

for an individual choosing house $\mathrm{i}$ in neighborhood $\mathrm{s}$. The variables $\mathrm{q}_{\text {is }}$ can be attributes of the house, such as number of rooms, condition of the street, etc. The variables $\mathrm{w}_{\mathrm{s}}$ are constant within a neighborhood, such as the quality of school or the distance to some important geographical point, such as a market or a river for recreational purposes or the central business district. The variable $y$ is income and $p_{\text {is }}$ is the price of the house. When $\eta_{\text {is }}$ is distributed as generalized extreme value (derived in McFadden, 1978), then the probability of choosing house $\mathrm{j}$, conditional on having located in neighborhood $\mathrm{s}$, is

$$
\operatorname{Prob}(\mathrm{j} \mid \mathrm{s})=\exp \left(\left(\alpha \mathrm{q}_{\mathrm{js}}+\beta\left(\mathrm{y}-\mathrm{p}_{\mathrm{js}}\right)\right) / \theta\right) / \sum_{\mathrm{k}=1}^{\mathrm{n}_{\mathrm{s}}} \exp \left(\left(\alpha \mathrm{q}_{\mathrm{ks}}+\beta\left(\mathrm{y}-\mathrm{p}_{\mathrm{ks}}\right)\right) / \theta\right)
$$

where $n_{s}$ is the number of houses to choose from in neighborhood $s$ and $\theta$ is a parameter of the generalized extreme value distribution. This expression shows the meaning of nested: the choices can be separated; conditional on the neighborhood, the household chooses a house. Then the household chooses a neighborhood. ${ }^{8}$ For the probability in (16), that is, the choice among alternatives within a neighborhood, IIA still holds. The ratio of probabilities of choosing $\mathrm{j}$ to choosing j', conditional on both being in neighborhood $s$, depends only on attributes $\mathrm{j}$ and $\mathrm{j}$ ' of the houses in the chosen neighborhood. However, the probability of choosing neighborhood $\mathrm{s}$ is

$\operatorname{Prob}(\mathrm{s})=$

$$
\left\{\sum_{\mathrm{k}=1}^{\mathrm{n}_{\mathrm{s}}} \exp \left(\left(\gamma \mathrm{w}_{\mathrm{s}}+\alpha \mathrm{q}_{\mathrm{ks}}+\beta\left(\mathrm{y}-\mathrm{p}_{\mathrm{ks}}\right)\right) / \theta\right)\right\}^{\theta} / \sum_{\mathrm{m}=1}^{\mathrm{s}}\left\{\sum_{\mathrm{j}=1}^{\mathrm{n}_{\mathrm{m}}} \exp \left(\left(\gamma \mathrm{w}_{\mathrm{m}}+\alpha \mathrm{q}_{\mathrm{jm}}+\beta\left(\mathrm{y}-\mathrm{p}_{\mathrm{jm}}\right)\right) / \theta\right)\right\}^{\theta}
$$

where $\mathrm{S}$ is the number of neighborhoods. This can be written as 


$$
\operatorname{Prob}(\mathrm{s})=\exp \left(\gamma_{\mathrm{s}}+\theta \mathrm{I}_{\mathrm{s}}\right) / \sum_{\mathrm{m}=1}^{\mathrm{s}} \exp \left(\gamma \mathrm{w}_{\mathrm{m}}+\theta \mathrm{I}_{\mathrm{m}}\right)
$$

by letting $I_{s}=\ln \left(\sum_{k=1}^{n_{s}} \exp \left(\left(\alpha q_{k s}+\beta\left(y-p_{k s}\right) / \theta\right)\right)\right.$. $I_{s}$ is the so-called inclusive value. The estimation can generally be thought of as first estimating the parameters of the housing choice, conditioned on the neighborhood as in (16) and then recovering $\gamma$ and $\theta$ by estimating (18). This is explained in Maddala, chapter 3. Further, programs such as LIMDEP now estimate the whole model simultaneously. Income will not influence any of the choices when it is linear as above. ${ }^{9}$ Choices depend on differences in utility and for linear utility functions, the difference is independent of income.

We can multiply (17) and (18) together to get the unconditional probability that house $\mathrm{j}$ is chosen:

$$
\operatorname{Prob}(j)=\operatorname{Prob}(j \mid s) * \operatorname{Prob}(s) .
$$

Then it works out that for two choices, one in neighborhood s and another in neighborhood s', the IIA no longer holds. These models are described in detail in Ben-Akiva and Lerman and in Maddala. Quite complicated versions of them can be estimated with LIMDEP. These models are frequently applied in recreational settings in the U.S. Morey (1994) and Bockstael et al. demonstrate their use in this context. In projects for the IDB, these models have been used more frequently for housing choices, where income is used to influence the alternative chosen. The welfare estimates proceed on the same principle as with the simpler discrete choice models. Both models assume that the randomness stems from imperfect observability of household preferences. The more complicated stochastic structure for the multiple choice models leads to a more complicated welfare measure. The mathematical expression differs because it is based on the expected maximum utility (from the observer's perspective).

As an example, let's use the specification in (15) to calculate the welfare effect of a change in $\mathrm{q}_{\mathrm{is}}^{*}$ where * denotes the new state and $\mathrm{q}_{\mathrm{is}}$ denotes the initial state. Then write $\mathrm{U}_{\mathrm{is}}=\alpha \mathrm{q}_{\mathrm{is}}+\gamma_{\mathrm{s}}+\beta(\mathrm{y}-$ $\mathrm{p}_{\mathrm{is}}$ ). Expected maximum utility for the generalized extreme value is (Hanemann, 1982, p.15)

$$
\mathrm{V}(\mathrm{p}, \mathrm{q}, \mathrm{y})=\ln \left(\sum_{\mathrm{s}=1}^{\mathrm{S}}\left(\sum_{\mathrm{i}=1}^{\mathrm{n}_{\mathrm{s}}} \exp \left(\mathrm{U}_{\mathrm{is}} / \theta\right)\right)^{\theta}\right)+\mathrm{k} .
$$

Using expression (4) and solving for cv gives 


$$
\mathrm{cv}=\left\{\ln \left(\sum_{\mathrm{s}=1}^{\mathrm{S}}\left(\sum_{\mathrm{i}=1}^{\mathrm{n}_{\mathrm{s}}} \exp \left(\mathrm{U}_{\mathrm{is}}^{*} / \theta\right)\right)^{\theta}\right)-\ln \left(\sum_{\mathrm{s}=1}^{\mathrm{S}}\left(\sum_{\mathrm{i}=1}^{\mathrm{n}_{\mathrm{s}}} \exp \left(\mathrm{U}_{\mathrm{is}}^{0} / \theta\right)\right)^{\theta}\right\} / \beta\right.
$$

Suppose that $\mathrm{q}_{\mathrm{i}}$ changes for $\mathrm{i}=1$ and $\mathrm{s}=1$. Then writing this expression out in full gives

$$
\begin{aligned}
& \mathrm{cv}=\left\{\ln \left[\sum_{\mathrm{s}=1}^{\mathrm{S}}\left(\delta_{1 \mathrm{~s}} \exp \left(\alpha \mathrm{q}_{11}^{*}+\gamma \mathrm{w}_{1}-\beta \mathrm{p}_{11}\right) / \theta+\sum_{\mathrm{i}=2}^{\mathrm{n}_{\mathrm{s}}} \exp \left(\alpha \mathrm{q}_{\mathrm{is}}+\gamma \mathrm{w}_{\mathrm{i}}-\beta \mathrm{p}_{\text {is }}\right) / \theta\right)^{\theta}\right)\right] \\
& \left.-\ln \left[\sum_{\mathrm{s}=1}^{\mathrm{S}}\left(\sum_{\mathrm{i}=1}^{\mathrm{n}_{\mathrm{s}}} \exp \left(\left(\alpha \mathrm{q}_{\mathrm{is}}+\gamma \mathrm{w}_{\mathrm{s}}-\beta \mathrm{p}_{\mathrm{is}}\right) / \theta\right)^{\theta}\right)\right]\right\} / \beta
\end{aligned}
$$

where $\delta_{1 \mathrm{~s}}$ equals 1 if $\mathrm{s}=1$ and 0 otherwise. This expression is just the new utility less the old utility, divided by the marginal utility of income, $\beta$.

Recent developments in random utility models relate to estimation. In particular, when there are many alternatives, the alternatives may be sampled to reduce the estimation burden. See for example, Parsons and Kealy and Ben-Akiva and Lerman on this issue. Further, the degree to which sites are aggregated is an especially important topic when the choices involve recreational sites. See Parsons and Needelman and Feather on this topic.

This section has reviewed the basics of welfare measures, or benefit measures, for the various kinds of projects and policies that agencies can bring about as a consequence of public investment and international lending. They permit benefit estimation for changes which are exogenous to households, and they are suitable for analyzing projects with multiple designs. ${ }^{10}$

\section{Aggregate Benefits}

In the benefit-cost analysis of projects, the calculation of benefits requires that the welfare measures calculated for individuals be added up for a total measure. Aggregation has a substantial impact on the benefit measures that are calculated yet it is a relatively neglected research area. It entails evidence or judgment on the 'extent of the market', as it is occasionally called (see Arrow et al., p.16). Yet the process of determining the extent of the market receives relatively little attention, both in reports on project analysis and in summary documents written in support of project analysis for the IDB (for example, see Carrizosa or Ardila). Writing down a simple scheme for aggregation serves as a basis for comparing a theoretically correct measure with what is practical.

Suppose that beneficiaries of the project are divided into $\mathrm{N}$ groups, with each group containing $n_{i}$ households. The household's benefit from the project will be $\operatorname{cs}\left(x_{i}, \beta\right)$, where $x_{i}$ measures the exogenous variables associated for the ith household (such as income, number in the household, level of education, etc.), $\beta$ is the vector of coefficients that explains how to compute the 
household benefit from the exogenous variables. Then the true value of aggregate benefits is given by

$$
B=\sum_{i=1}^{N} n_{i} \operatorname{cs}\left(x_{i}, \beta\right)
$$

Now imagine the sources of error for benefits. They can come from having the wrong values for households, or from the wrong number in the ith group. Assuming the group number and the associated measure of benefits to be independent, we can calculate the variance of B as:

(22) $\operatorname{Var}(\mathrm{B})=\sum_{\mathrm{i}=1}^{\mathrm{N}}\left[\left(\mathrm{n}_{\mathrm{i}}\right)^{2} \operatorname{var}(\mathrm{cs})+\operatorname{cs}\left(\mathrm{x}_{\mathrm{i}}, \beta\right)^{2} \operatorname{var}\left(\mathrm{n}_{\mathrm{i}}\right)\right]$

This suggests that researchers need to pay attention to the number of households as well as the benefits per household.

One issue not explicitly dealt with in writing out aggregate benefits as in (21) concerns the aggregation of attributes or determinants of benefits. Suppose that index i now refers to neighborhoods, and $\mathrm{x}_{\mathrm{i}}$ is the mean level of attributes per household in the ith neighborhood.(I.e., $\left.\mathrm{x}_{\mathrm{i}}=\sum_{\mathrm{j}=1}^{\mathrm{n}_{\mathrm{i}}} \mathrm{x}_{\mathrm{ij}} / \mathrm{n}_{\mathrm{i}}.\right)$ Then taking the mean attribute level per neighborhood and evaluating it with the function $\operatorname{cs}\left(x_{i}, \beta\right)$ will underestimate mean willingness to pay if cs is convex in $x_{i}$ and overestimate if concave in $\mathrm{x}_{\mathrm{i}}$. Since most functions are concave in attributes (e.g., indirect utility functions), this would typically imply overestimation. For example, when the demand for a particular good is given by the Marshallian demand function $x=a+b p$, where $p$ is the price and $(a>0, b<0)$ are estimated parameters, consumer surplus is given by $-x^{2} / b$. For example, let $b=-1$ and suppose that there are two individuals, $x=1$ and $x=9$. In this case, consumer surplus at the is mean is 25 but mean consumer surplus 42 .

\section{Practical Guidelines: Assuring ApPropriate Methods}

Assuring appropriate methods for benefit estimation requires that the appropriate techniques are known and that they are used. The greater problem is the latter. The challenge is to design cost-effective ways of guaranteeing that benefits and costs are handled correctly. The following two sections address these problems for contingent valuation and for hedonic methods, the two main tools of benefit evaluation for development projects.

\section{IVA. Methods for Contingent Valuation}

The debate over the whether it is possible to estimate nonuse or existence values with contingent valuation, and the growth in confidence in contingent valuation for use values has generated a large literature exploring the method. There is ample evidence that the more formal 
parts of this literature have permeated the culture of development economics. For example, the papers by Ardila and Carrizosa demonstrate a sophisticated level of understanding of technical material. Other research efforts by project economists provide quite advanced methods for benefit assessment (Niklitschek and Leon). Further, one can find ample material on how to do cv in the published and gray literatures. Consequently, this section will provide a quick review of standards for doing contingent valuation. The focus will then change to questions of how to design reporting of $\mathrm{cv}$ results to provide incentives to follow the appropriate methods.

\section{IV.A.1 Reasonable Practices for Contingent Valuation}

1. Questionnaire design. Questionnaires should be designed, tested and revised. Various informal methods of testing questionnaires should be used. Current practices have centered around focus groups for questionnaire testing. But the essential elements of questionnaire testing involve assessing the expected population's understanding of the questionnaire. This can be accomplished in a variety of ways, including focus groups and face-to-face interviews following completion of pilot questionnaires. The consultants or researchers who are doing the study should be present to get direct feedback about the questionnaire. In the best of circumstances, economists should work with survey design specialists. If visual aids, such as drawings, photographs or charts, are used, there should be demonstrable confidence that these are understood.

2. The characterization of the scenario. Is the scenario described in terms of service flow? For example, in the case of constructing a drainage system, the service flow would be protection from floods. The respondent needs to know what the project will mean in terms of reduced risk from floods, not that a drainage system is being constructed. It is up to the interviewer to ensure that the nature of the services to be received (or lost ) is evident to the respondent. Especially in the case of environmental services, such as clean water, this is quite demanding. Photographs, drawings, and other details can be used, and the extensive help of survey design specialists is ideal.

3. If a referendum question is used, a nonresponse alternative should be offered. Further, the payment vehicle, whether taxes, price, or other, must be credible. The referendum model is recommended by the NOAA panel because it appears to be incentive compatible. That is, if the respondent wants to influence the aggregate outcome, he will not know whether to answer yes or no to a given price, unless he knows how others answer. However, referendum models require more observations to obtain the same level of precision as a simple open ended question. (See Carson, and the extension in Alberini and Carson.)

4. In answering the willingness to pay question: 
- remind the respondent of other alternatives, where appropriate;

- $\quad$ when the respondent replies yes, ask the respondent where the money would come from;

- when no or nonresponse is the answer, ask why.

The NOAA report suggests that reminding respondents that they can spend money on other services or that there are substitute services which could also be purchased is a practical way to prevent overestimation of willingness. In a test of this proposal, Loomis et al. (1994) found no significant difference between two sets of parameters, one estimated from a sample who were reminded of the availability of substitutes and one from a sample not so reminded. The problem of budgets and substitutes seems less severe for private goods where households have a great deal more experience in actual choices.

5. Use a probability sample, so that the probability of selecting the household is known or can be estimated. Interviewing conducted in urban areas of households in established residences is typically the case. This type of surveying is relatively easy to extrapolate, at least for project analysis. Using a probability sample means that the consultant can have more confidence in the aggregation of the results.

6. A practical way of showing that the questionnaire is understood is to test for scope. Scope in this context generally refers to an increase in the quantity or quality of the service flow. In terms of the utility function, scope means that the service goes from $\mathrm{q}$ to $\mathrm{q}+\Delta \mathrm{q}$ or from $\mathrm{q}_{1}, \mathrm{q}_{2}$ to $\mathrm{q}_{1}+\Delta \mathrm{q}_{1}, \mathrm{q}_{2}+\Delta \mathrm{q}_{2}$. For example, a project which offers water and electricity compared with just water has expanded scope. A project which offers sewer hookup and water has expanded scope over just water. It is necessary that increases in scope increase the willingness to pay. But scope is not linear, and can be confounded with embedding. Design the questionnaire so that aspects of the project can be tested. Tests for scope were an important element in NOAA panel discussions and its final document. Splitting the sample so that the scope of the project changes across projects can help check reliability of results. If the scope increases, then estimated willingness to pay ought to increase. For example, households receiving drainage and sewer hookup should be willing to pay more, on average, than households receiving only sewer hookup. This notion can be tested by devising several questionnaires, one asking about sewer only, one sewer and drainage, and one about drainage only.

7. Sensible estimation techniques. Some exploration of the data should confirm that the model is not overly sensitive to specification in terms of included or excluded variables. Reasonable specifications imply that variables roughly implied by utility maximization should be 
included. More important, a decent specification should not include variables which are practically the same as the referendum response. Questionnaires for sewer hookups occasionally ask the respondent whether he would hook up within a reasonable time period if he answers yes to the initial referendum model. For example, in the study of a collector line for the Tiete, following the basic yes-no contingent valuation question, there is a question asking the respondent whether he would sign a commitment for the willingness to pay. In the estimation of a discrete choice equation, the use of the second response as a regressor is not legitimate because yes to the second question is not possible for no to the first question. Yet it can have a profound effect on the fit of the model, making a model with otherwise poor explanatory power appear more powerful.

9. Is the extent of the market well defined? This pertains especially to aggregation, as discussed in section III above. Calculating aggregate benefits from the sample does not usually receive much attention, but can have a big impact on the total benefits from the project, especially in expanding sample means or totals to a population.

10. Calculating Benefits. Sometimes, especially for referendum models, analysts may have several choices about how extreme estimates of willingness to pay are treated. Sometimes estimates may be negative and sometimes very large. The method of calculation should make clear the degree to which individual results are truncated from above or below, and the sensitivity of the aggregate benefits to such truncation.

These procedures for using contingent valuation reflect practices where there is reasonable agreement among researchers about the proper procedures. Several areas within contingent valuation are emerging as important and as yet unresolved. The following section addresses some of these topics, especially as they relate to problems likely to be encountered in developing countries.

IV.A.2. Several Outstanding Issues for Contingent Valuation.

In applications for development banks, contingent valuation is frequently used in countries where inflation is far greater than in the U.S., where most of the CV experience has been accumulated. The questions and answers should be in real incomes, not nominal. Otherwise the answer will not reflect current willingness to pay. For example, in a project in Fortaleza, the questionnaire asks (after translation): "One way of paying for the works would be through a monthly tariff which would be adjusted in accordance with inflation"[italics added ${ }^{11}$. Here the adjustment for inflation is explicit. Similar adjustments are made in other studies. 
Inflationary concerns are a component of the general problem of temporal resource allocation. A fundamental problem for projects which provide services for long periods of time, for example sewer systems, exists when the present discounted willingness to pay for a representative individual exceeds the per capita cost of the project but current willingness to pay is less than the per capita cost. That is,

$$
\operatorname{cv}(0)<\mathrm{C} / \mathrm{n}
$$

where $\operatorname{cv}(0)$ is the current (year 0 ) willingness to pay for the project by a representative household, $\mathrm{n}$ is the number of households and $\mathrm{C}$ is the total cost of the project. This is typically the case for large investments--willingness to pay out of current income is not sufficient to warrant project support. However, the present value of willingness to pay may exceed the per capita household cost:

$$
\sum_{t=0}^{\mathrm{T}} \operatorname{cv}(\mathrm{t})(1+\rho)^{-\mathrm{t}}>\mathrm{C} / \mathrm{n}
$$

To answer yes or no to a referendum question, the respondent is forced to do a capital market calculation, at least implicitly, and to figure out whether the temporal flow of services is worth the initial cost. When the respondent performs this calculation, $\rho$ is the personal discount factor. $\mathrm{T}$ is the number of time periods over which the services are discounted. This comparison presents a variety of challenges. One is the absence of well developed credit markets. The other is inflation, which has already been discussed.

Frequently, when the initial cost is high, it is obvious that a household would not pay its share of the total cost, $\mathrm{C} / \mathrm{n}$, out of current income. Then the respondent must be asked a periodic payment. For example, a simple referendum question might be stated: would you pay $\$ \mathrm{f}$ per month for the next $\mathrm{T}$ months? And the question must make clear the periodic and repeated nature of the payments. In a referendum setting, the respondent would answer yes if

$$
\sum_{\mathrm{t}=0}^{\mathrm{T}} \mathrm{V}\left(\mathrm{p}_{\mathrm{t}}, \mathrm{q}^{*}, \mathrm{y}_{\mathrm{t}}-\mathrm{f}\right)(1+\rho)^{-\mathrm{t}}>\sum_{\mathrm{t}=0}^{\mathrm{T}} \mathrm{V}\left(\mathrm{p}_{\mathrm{t}}, \mathrm{q}^{0}, \mathrm{y}_{\mathrm{t}}\right)(1+\rho)^{-\mathrm{t}}
$$

Does the present value of utility, with the project and with income minus the payment, exceed utility without the project, when both are discounted at a personal discount rate? If the capital market does not work, or the household is not a familiar participant in it, then two problems are created. First, households may not be in equilibrium over time, so that they will not be indifferent to the reallocation of a stream of payments with a constant present value. Hence a household might answer yes to (23) but no to a question that subtracts the entire hypothetical fee from current income: 


$$
\mathrm{V}\left(\mathrm{p}_{0}, \mathrm{q}^{*}, \mathrm{y}-\mathrm{F}\right)+\sum_{\mathrm{t}=1}^{\mathrm{T}} \mathrm{V}\left(\mathrm{p}_{\mathrm{t}}, \mathrm{q}^{*}, \mathrm{y}_{\mathrm{t}}\right)(1+\rho)^{-\mathrm{t}}>\sum_{\mathrm{t}=0}^{\mathrm{T}} \mathrm{V}\left(\mathrm{p}_{\mathrm{t}}, \mathrm{q}^{0}, \mathrm{y}_{\mathrm{t}}\right)(1+\rho)^{-\mathrm{t}}
$$

where $\sum_{t=0}^{\mathrm{T}} \mathrm{f}(1+\rho)^{-\mathrm{t}}=\mathrm{F}$. (That is, the stream of payments $\mathrm{f}$ has the same present discounted value as the single one time payment F.) For this comparison and (23) to give the same answer, it is necessary that the household be in equilibrium, just as it is for the static welfare case.

Consequently, in the absence of credit markets, designing the survey to ask the question with a periodic payment seems the more practical approach. For example, a question might be phrased as "Would you pay a fee of $f$ per month for the next 5 years?" While this question may reduce the temporal timing issue, it creates an additional problem: differences in $\rho$ across households. This rate of discount will now be a personal value, strongly dependent on income and real wealth, not a market rate. Only a well functioning capital market will equilibrate personal discount rates with the market rate of interest. In the absence of such equilibration, the rate used in a hypothetical question may be a nominal rate or a real rate or may legitimately vary for other reasons. Consequently sample splitting for testing the impact of different temporal payment schemes will be an ambiguous test of temporal inconsistencies. Special care should be taken to ensure that the respondents understand the question in the way researchers have intended.

The temporal issue can be seen from a question from a project involving a drainage system for the Tiete in Sao Paulo. This question follows a careful explanation of the project, with pictures, which demonstrates the nature of the services. Part of the question reads, after translation:

"That a trunk line be constructed, receiving the sewage, and paying $\$ X$ per month, adjusted" [italics added $]^{12}$.

Here the respondent is being asked whether he will pay a monthly fee, adjusted for inflation. However, the timing is not clear. Is the payment implied by this question for one year, two or indefinitely? Naturally, the difference in values is quite great. This problem, known as temporal embedding, has appeared in several unpublished studies in the U.S. One manifestation of the problem occurs when responses to discrete choice cv questions do not change when the timing of payments changes, implying quite different present values for the answers. A reasonable way of demonstrating that the temporal problem has been handled is to do sample splitting, changing the timing of payments among subsamples. 
A recurring problem in using the referendum model is the prediction of negative willingness to pay. Expression (10) shows that the expected value of an individual's willingness to pay is

$$
\mathrm{E}(\mathrm{cv})=(\alpha+\gamma \mathrm{s}) / \beta,
$$

where $\gamma$ is a vector of coefficients and s a corresponding set of variables that influence utility or willingness to pay. It is entirely possible that $\mathrm{E}(\mathrm{cv})$ will be negative. This can be illustrated with a model estimated from a Montevideo study. The study, described in more detail in McConnell and Ducci, asks a referendum question about cleaning up a particular set of beaches in Montevideo by constructing a collector system for household and industry wastes. For the study, 1500 households were interviewed. The following discrete choice model was estimated:

$\operatorname{Prob}($ yes to question $)=-1.34+.36 \mathrm{ylevel}+.88 \mathrm{dwest}+.52 \mathrm{dbeach}+.52$ age $-.000036 \mathrm{tax}$

where

$$
\begin{aligned}
& \text { ylevel = } 1 \text { if household income above the low income level; } \\
& \text { dwest = } 1 \text { for households who plan to use the beaches to be cleaned up; } \\
& \text { dbeach = } 1 \text { if household is a beachgoing household; } \\
& \text { age = } 1 \text { if household head is less than } 60 \text { years old; } \\
& \operatorname{tax}=\text { the proposed municipal tax. }
\end{aligned}
$$

The coefficients are all different from zero at a high level of significance. Willingness to pay is given by

$$
\mathrm{cv}=(-1.34+.36 \mathrm{ylevel}+.88 \mathrm{dwest}+.52 \mathrm{dbeach}+.52 \mathrm{age}+\varepsilon) / .000036 .
$$

Then the expected willingness to pay is

$$
\mathrm{E}(\mathrm{cv})=(-1.34+.36 \mathrm{ylevel}+.88 \mathrm{dwest}+.52 \mathrm{dbeach}+.52 \mathrm{age}) / .000036 \text {. }
$$

Suppose that ylevel, dwest, dbeach, and age are all equal to zero. The expected willingness to pay is

$$
\begin{aligned}
\mathrm{E}(\mathrm{cv}) & =-1.34 / .000036 \\
& =-44,667
\end{aligned}
$$

That is, the predicted willingness to pay for such an individual is estimated to be negative. For a good such as a clean beach, where the household has the simple option of not visiting the beach, a negative willingness to pay is not logical. In more academic research, one can get by with simply describing the distribution of willingnesses to pay. But in project analysis, it is necessary to obtain a number which represents the mean or aggregate willingness to pay. 
There are several not very satisfactory options to the negative willingness to pay. Some are discussed in the exchange between Hanemann (1989) and Johanson, Kristrom and Maler. The first option is simply to ignore the negatives and suppose that they are simply part of the broader uncertainty about the model. The second option is to truncate all willingnesses to pay at zero. This is more logical, but it yields a higher estimate without a corresponding adjustment for the upper end of the distribution. One ad hoc procedure would be to truncate the willingness to pay from below at zero and from above at the maximum bid put to the consumers. The difficulty with any truncation of willingness to pay is that it treats the computing of willingness to pay with one set of stochastic assumptions and the error for estimation with another set. ${ }^{13}$

The problem of negative willingness to pay arises in part due to the linear utility function and additive error. In this specification, the probability of a yes is given by

$$
\operatorname{Prob}(\text { yes })=\operatorname{Prob}(\alpha+\gamma s-\beta \operatorname{tax}+\varepsilon>0)
$$

where $\alpha+\gamma \mathrm{s}-\beta \operatorname{tax}$ is the linear utility difference and $\varepsilon$ is the additive (typically normal or logistic) mean zero error. Now consider the probability of a yes when the tax is zero:

$$
\operatorname{Prob}(\text { yes } \mid \operatorname{tax}=0)=\operatorname{Prob}(\alpha+\gamma \mathrm{s}+\varepsilon>0) .
$$

Here even if the tax is zero, the probability is less than one that the household will take the service, no matter how high its willingness to pay. Presumably, if the good is really worth something, then when the tax, fee or price is zero, the household will say yes with certainty. An example of the relationship between the probability of a yes and the tax or fee can be seen in the Fortaleza analysis, the graph DAP Fortaleza (figure 1, grafico II.2.1), where the percent of respondents willing to pay a monthly price is on the vertical axis, and the monthly price on the horizontal axis. As in Figure 3. All three graphs intersect the vertical axis at 80 or 85 percent as the price goes

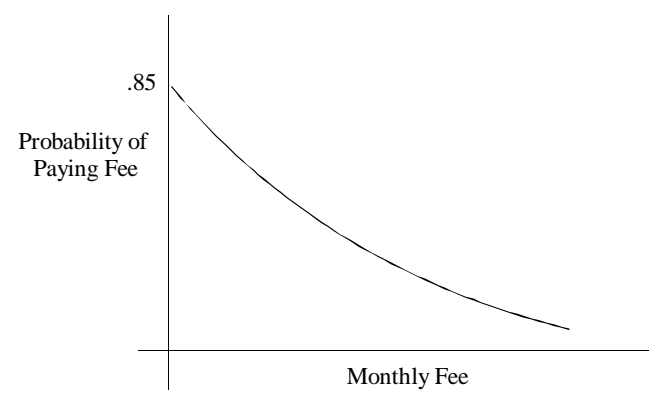

Figure 3.

goes to zero. This graph which should go to one as the monthly fee goes to zero, approaches the ideal more closely than many in the literature. 
The conditional mean willingness to pay can be better understood with the help of a simple graph. Put the probability that a household will pay the hypothetical fee on the vertical axis and the fee itself on the horizontal axis. In particular, if this graph intersects the vertical axis at less than .5 , then the mean willingness to pay will be negative. We can see this by recalling that for any continuous random variable $\mathrm{z}$, the mean can be written

$$
\mathrm{E}(\mathrm{z})=\int_{0}^{\infty}(1-\mathrm{F}(\mathrm{z})) \mathrm{dz}-\int_{-\infty}^{0} \mathrm{~F}(\mathrm{z}) \mathrm{dz}
$$

where $F(z)=\operatorname{Prob}($ random variable $<\mathrm{z}$ ) is the cumulative distribution function of $\mathrm{z}$ (see for example, Rohatgi, p.86). The probability that a household will pay a price or fee equal to $\mathrm{P}$ is just Prob(willingness to pay $>\mathrm{P}$ ), which equals 1 - Prob(willingness to pay $\leq \mathrm{P}$ ). Common sense argues that it should intersect the vertical axis at 1 , which is equivalent to Prob(willingness to pay $\geq 0$ ) $=1$. If this curve does indeed intersect the vertical axis at 1 , then the second term on the right hand side of $\mathrm{E}(\mathrm{z})$ is zero and subtracts nothing from the mean--which is then strictly positive. For symmetric distributions, if the graph intersects the vertical axis at less than .5 , then the negative

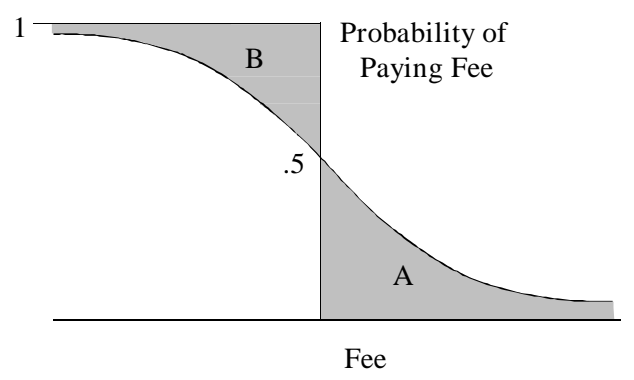

weight is greater than the positive weight, and the

Figure 4. expected value will be negative. This is demonstrated in Figure 4, where the shaded area B is subtracted from the shaded area A to compute the mean. If the distribution is symmetric and the probability is less than .5 at a zero fee, the mean will be negative. As drawn in Figure 4, A equals B so the mean equals zero.

One method of handling this problem is to specify the behavior in terms of a non-linear willingness to pay function and a multiplicative error. For example, a model that works is

$$
\begin{aligned}
\operatorname{Prob}(\text { yes }) & =\operatorname{Prob}(\exp (\alpha+\gamma \mathrm{s}) \varepsilon>\operatorname{tax}) \\
& =\operatorname{Prob}(\alpha+\gamma \mathrm{s}-\log (\operatorname{tax})+\mathrm{u}>0)
\end{aligned}
$$

where $\mathrm{u}=\log (\varepsilon)$ and $\varepsilon$ is $\operatorname{lognormally}$ distributed. The willingness to pay function is simply stated as willingness to pay $=\exp (\alpha+\gamma s) \varepsilon$. This model cannot be derived from a utility-theoretic setting, because it would imply a nonlinear income effect. It is, however, a useful model and the approach 
of specifying a willingness to pay function has the advantage of being direct. See for example, Cameron and James. To estimate this model, one simply makes the probability of a yes depend on the vector $\mathrm{s}$ and $\log (\operatorname{tax})$ (or price or payment). A probit model then gives back the normalized parameters $(\alpha / \sigma, \gamma / \sigma,-1 / \sigma)$ as the constant, the coefficient on s and the coefficient on $\log (\operatorname{tax}){ }^{14}$ To recover the true (that is unnormalized) parameters simply divide the coefficient on the covariates $\mathrm{s}$ by the negative of the coefficient on the tax: $\alpha=(\alpha / \sigma) / 1 / \sigma, \gamma=(\gamma / \sigma) / 1 / \sigma$. Then the willingness to pay function is given by $\exp (\alpha+\gamma s)$ for the median willingness to pay. ${ }^{15}$

One solution to the estimated negative willingness to pay is to use non-parametric methods. These methods are attractive quite because they make minimal assumptions about underlying preferences and the distribution of random elements. The Turnbull distribution, described in the Appendix, has been used extensively by Richard Carson and associates at NRDA, and is useful in applications and also for its intuitive clarity.

Several additional topics have recently been developed in the CV literature: the distribution of the estimate of willingness to pay, the use of joint behavioral-hypothetical information in a single model, and advances in the design of questionnaires. Concerning the distribution of willingness to pay, a household's willingness to pay is generally modeled as a random variable, yet its expectation is treated as if the vector of parameters were known with certainty. Researchers are now investigating this distribution by constructing confidence intervals about the mean. See for example, Cooper and his references. These intervals take into account not only the randomness of the error, as it shows for example in expression (27), but also the randomness of the coefficients, which are after all distributed aysmptotically normally. The methods are quite computer intensive, and do not lend themselves to quick adaptation to project analysis. In the use of these methods so far, there is little evidence that the confidence intervals are unacceptably large.

Estimating joint behavioral-contingent valuation models is part of an effort to add support to both kinds of methods. The basic idea is that behavior typically reveals some kind of evidence on willingness to pay, which can be used in conjunction with contingent valuation questions. Adamowicz, Louviere and Williams estimate the demand for environmental amenities using this approach. In an interesting application, Niklitschek and Leon use behavioral intentions and contingent valuation in a joint estimation procedure. This approach receives its fullest treatment from Eom and Smith, which typifies the move toward more complex survey design, especially in comparison with the simple discrete choice. 
Two interesting and potentially useful developments in questionnaire design could be relatively easily incorporated into project analysis. One concerns the optimal design of bids, taxes or prices. In a typical CV study, researchers explore the maximum willingness to pay, perhaps by comparing the bids with income or just with good intuition. And this will usually give reasonable results. But it can be shown that through careful selection of the intervals between bids, greater efficiency can be achieved. Kaninen describes optimal experimental designs for survey questionnaires. (See also the papers by Cooper, Duffield and Patterson, and Nyquist.) Related to the optimal bid design literature is the idea of double bounded CV. In this approach, the respondent is asked two questions. The second question depends on the answer to the first. For example, the first question may ask if the respondent would pay $\$ \mathrm{X}$, a standard referendum question. The respondent is then asked if he would pay $\$ \mathrm{X}-\Delta \mathrm{X}$ if he answers no to the first question and $\$ \mathrm{X}+\Delta \mathrm{X}$ if he says yes to the first question. A yes-no or no-yes pattern of responses completely bounds the individual's willingness to pay, while a yes-yes or no-no response provides more information without bounding. The double-bounded model is explored in Hanemann, Loomis and Kanenin, where it is demonstrated that this approach improves the efficiency of estimates.

These ideas of how to do good CV work, from the formation of questionnaires and optimal bid levels to the use of double bounded dichotomous questions, are widely disseminated. See for example, Arrow et al. Standard practices are increasingly becoming part of every CV study. Much of the progress in contingent valuation has come at the impetus of damage assessment. Research under damage assessment, with the threat of adversarial proceedings, may take several years and can often generate seemingly unlimited research support. Naturally the circumstances for project analysis, where time and technical support are the most important constraints, differ substantially. Nevertheless, the lessons learned can increasingly be put to good use in project analysis.

\section{IV.A.3. Reporting Results for Contingent Valuation.}

The problem of demonstrating that appropriate methods have been adopted can be aided by employing reporting standards. These standards would provide information that an economist would need in order to understand the project analysis from afar. A uniform way of reporting would lend credence to good project analysis. The following should be considered as preliminary recommendations:

1. Make the data from the survey available. Having access to datasets allows others to replicate results. The reporting would provide the final questionnaire, a data guide from the 
questionnaire to the dataset which tells which variable on the data set corresponds to which question, and then the untransformed data.

2. Show the history of questionnaires. A set of questionnaires, from the initial draft to the final instrument would reveal the evolution of questions. Such a set is provided in the report by Research Chile.

3. Do sensitivity analysis for statistical work. It is not difficult to estimate a variety of models and to display the results. The most important determinant of estimates of mean willingness to pay for referendum models is usually the coefficient on the proposed payment. Sensitivity analysis should show that this coefficient is stable under different specifications.

An essential element of testing for robustness of models, parameter estimates and welfare measures is the reporting of results when these measures are not robust. In the case of especially fragile models, it is especially worthwhile to report the variations in benefit estimates from different models. If welfare measures vary substantially with small changes in the specification of the model, there is some reason to be concerned with the results. It should be an essential part of the reporting process that benefits be calculated and reported with different models, not simply random variations of a chosen model. The variation across models captures uncertainty about parameters within a model, and this is probably the greatest source of uncertainty from contingent valuation or behavioral models.

4. Provide simple descriptive statistics on the sample size, the proportion of the sample used in the econometric analysis, the percent responding yes or no to the referendum question and the range of prices (bids, or other vehicles in contingent valuation). For example a table showing for each bid range the proportion of yes or no responses can be used to approximate welfare effects, and hence is a useful check on the econometrics. As described in the appendix, such a table can give all the parameters of a robust lower bound estimate of willingness to pay, based on the Turnbull distribution function. The report by Research Chile is an example which provides very good empirical support for the contingent valuation.

5. Calculation of benefits. How has the extent of the market been determined? If a referendum model has been used, does it estimate negative values for benefits? Reporting this information as part of project analysis would enable the results to be replicated and the propriety of the benefits estimation to be assessed.

6. If the results are not trustworthy, forego making estimates of benefits. Project analysis can have several outcomes. It can show that benefits are less than costs or benefits are greater than 
costs. But if results are not robust, the benefit analysis may fail to show any decisive result. When results are inconsistent, illogical, or especially sensitive to assumptions or procedures, this should be reported. In such cases, benefit analysis fails to reveal whether the project is worth adopting and the benefit analysis should state that conclusion. Reporting that results are inconclusive may lead to a better understanding of these results and better practices in the long run.

\section{IVB. Methods for Hedonic Valuation}

Hedonic methods have a longer history in development projects than contingent valuation methods. The ideas behind hedonic models have formed the basis for the analysis of many projects which enhance housing sites. In some ways, however, it is more difficult to understand fully the circumstances around hedonic models than for contingent valuation methods. A good contingent valuation study can clearly explain the circumstances of choice, while such circumstances may be ambiguous even to researchers or consultants who work on a hedonic valuation project. This problem is compounded by the considerable differences in the functioning of housing markets in different countries.

Hedonic models have been used with such frequency that they are a widely accepted tool. Standard references for hedonic models include Bartik and Smith for urban amenities, Palmquist for environmental amenities, and Freeman, chapters 11 and 12, for a broad overview.

Good operating practices in estimating hedonic models have not changed over the past decade, though we have learned a bit more about how various practices influence results. The basic empirical issues in hedonic models are the following:

1. multicollinearity

2. market definition

3. functional form

The basis for collinearity in hedonic markets is created by the market itself. Housing services come in bundles where, based on preferences and incomes, good services get bundled together and inferior services get bundled together. Houses with paved streets, water and sewer connections and telephones go together while houses with no sidewalks, no running water and poor schools often come in a separate bundle. Supply responds to higher incomes by increasing attractive attributes and decreasing unattractive attributes. It is such a common problem that Belsley, Kuh and Welch use a hedonic price equation as a classic example of multicollinearity.

The basic estimating issue for hedonic models concerns the implications of multicollinearity. Trying to include too many attributes will result in large standard errors and 
imprecise parameter estimates. Excluding variables may impart a bias to the remaining parameters, because the market and preferences induce systematic correlation among all the attributes of housing. Collinearity among locational variables, such as distance to the city center or to other amenities such as bus stop or health center are somewhat collinear by their construction: being closer to one place means being farther away from another. There is no neat solution to the problem. Two practical methods of assuring that hedonic models are robust would be to report a measure of the collinearity among variables included in the final model, and to demonstrate with a variety of different specifications that the marginal prices of the relevant variables are stable. When the hedonic price function is used to predict the price of complete bundles of housing services--different kinds of houses--the problem of collinearity is not as severe as long as a reasonable set of attributes is included.

The problem of functional form is also troublesome, and interacts with multicollinearity. Again, neat solutions are not available, and the best response to skepticism about results is to demonstrate the robustness of marginal prices under different functional forms. There is some simulation evidence (see Cropper et al., 1988) that a simple Box-Cox transformation provides a good approximation. And intuition and more simulation results by Cropper et al. suggest that forms with interaction terms, such as a simple quadratic and a Box-Cox quadratic, induce considerable additional collinearity through the extra terms, and probably should be avoided.

The extent of the market means what kinds of different housing markets should be included in a single hedonic price model. The trade-offs involve the larger number of observations that come from including houses from more diverse markets versus the misspecification that arises when different markets are combined into one hedonic price function. ${ }^{16}$ Particular difficulties are created when one market has an attribute and another does not. Then the problem of specification and collinearity is especially severe. For example, suppose that we estimate a hedonic price function for two neighborhoods--one with a sewer connection and the other without. In order to infer that the coefficient on the attribute 'sewer connection' truly reflects the marginal value, we have to be assured that all of the attributes from each neighborhood are included in the hedonic price function. Otherwise, the 'sewer connection' will carry with it the effect of all the attributes that are unmeasured. And since good attributes tend to be bundled together, the net effect is likely to be an overestimate parameter or marginal price of the 'sewer connection' attribute.

A reasonable approach to separating housing markets was accomplished in the study by Figueroa for Research Chile, given the goal of predicting the value of a house. In this study of 
housing markets in Paraguay, hedonic price models were estimated for four cities. The specification for each city was different. Across the four models, only the two variables 'area construida' and 'nivel socioeconomico del vecindario' were included in each model. The estimation of these models followed the usual practice of measuring the size of the house in part by the number of rooms, but this variable was included differently in each model, sometimes as bedrooms, sometimes as bathrooms and sometimes not at all. The fact that the specifications were different reduced the impact of collinearity without causing serious problems in this study, because the object of the analysis was the prediction of the total price of housing services. If the study had attempted to estimate the marginal price of an attribute, then this approach would be questionable. Clearly, pooling the observations and estimating the same hedonic price function for all cities in the study could result in quite different numerical estimates of parameters and predicted prices since market opportunities of households in different markets vary.

Care should be taken with the multiple city hedonic model in comparing predicted housing prices or marginal prices of attributes among cities. Such a comparison may be confounded by differences in price levels or wage rates. Wages may adjust to account for differences in specific amenities as Hoehn, Berger and Blomquist argue. ${ }^{17}$ They also adjust to price level differences. Consequently, it is more reliable to use the hedonic price equation within the area where it is estimated, rather than comparing estimates across areas.

A final concern is the degree to which the housing market functions. If markets are thin or transactions costs high, there will be few transactions. The nature of ownership varies considerably among countries, in some cases including title to the land, in other cases not. The working of the housing markets is not well documented in typical hedonic studies. These workings will be strongly affected by local conditions such as the tax structure and inflationary expectations, and the degree to which these influence housing markets. To be confident that the hedonic market really functions, good descriptive material on the market should be provided.

Here are a few suggestions for demonstrating the validity of the hedonic studies. They are similar in spirit to the suggestions for contingent valuation.

1. Provide a description of the housing market. What are the impediments to sales? Are the sales arms length transactions? How big is the housing market being analyzed? Are different neighborhoods or cities included in the same hedonic equation?

2. Provide the data. A copy, electronic and printed, of the data, with the variables clearly named, would help others to replicate the analysis. 
3. Demonstrate the robustness of the results on marginal prices by showing that marginal prices are not excessively sensitive to changes in functional form or to the set of included variables. Given the computer technology, this is not an onerous requirement, and it can go a long way toward supporting results.

4. Provide simple descriptive statistics, including mean prices, mean attribute level per house, the number of house sales used versus the number available in the survey.

5. As in the contingent valuation procedures, hedonic results which are especially sensitive or inconsistent should not be the basis of project analysis. The benefit analysis should recognize such possibilities.

\section{IVC. Estimating Multiple Choice Models}

The handling of multiple choices arises in a variety of different ways in benefit analysis. One context is the choice among alternatives, discussed at the beginning of this paper. This can happen in the housing market, where the alternatives are different houses. Another application occurs in recreational choice, especially when the recreational choices are influenced by water quality which stand to be improved by sewage treatment plants or sewer connections. Still other applications of multiple choice models have been developed in contingent valuation studies, where households have been offered not a simple dichotomous choice, as in the referendum model, but multiple hypothetical choices.

One especially interesting application of this method is provided in the report by Research Chile. In this study, households are offered three alternatives to their current housing. The three housing alternatives have well specified attributes. The size of the lot is made explicit, the form of household sanitation is given, as well as the nature of the streets (paved or not) and other aspects of the neighborhood. Several aspects of this approach are worth considering. To analyze the projects let

$$
\mathrm{U}_{\mathrm{i}}=\mathrm{V}\left(\mathrm{q}_{\mathrm{i}}, \mathrm{y}-\mathrm{p}_{\mathrm{i}}\right)+\varepsilon_{\mathrm{i}}
$$

be the utility from the ith alternative for $\mathrm{i}=1,4$, where the $\mathrm{q}_{\mathrm{i}}$ 's represent the measured attributes of the alternatives and $p_{i}$ their prices. The questionnaire clearly ranks the alternatives. The present residence of the household is inferior to the others, at least in principle, (although this may not be well known). In general we believe that

$$
\mathrm{V}\left(\mathrm{q}_{\mathrm{i}}, \mathrm{y}\right)>\mathrm{V}\left(\mathrm{q}_{\mathrm{i}-1}, \mathrm{y}\right) \text { for } \mathrm{i}=2,3,4 \text {. }
$$


Consequently, in order to use the random utility model framework, it is necessary to put prices in the questions such that $p_{i+1}>p_{i}$ for $i=1,2,3$. Otherwise, the respondent would always choose alternative 4 .

The second aspect concerns the assumption of the independence of irrelevant alternatives. In the work by Research Chile, the choice among these alternatives is modeled in a simple conditional logit framework, which assumes independent errors. This implies, as discussed above, that the ratio of probabilities between any two alternatives is independent of what is happening in the other alternatives. However, in this case, it is likely that utility from choices 2, 3, and 4 are correlated. Ignoring this correlation will overestimate the probability of choosing options 2, 3, 4 . One way of interpreting this overestimation is in the alternative-specific dummy variables. These are variables which show the innate attractiveness of each alternative. Although only n-1 constants can be estimated for choices among $\mathrm{n}$ alternatives, each constant serves as the alternative dummy for the alternative not included. These will be too high for 2,3 , and 4 and too low for 1 . The result will be underestimation of the benefits of alternative 1. A more general approach would be the nested logit. The first stage to be estimated is the probability that the household would choose one of the improved residences. Then, conditioned on choosing one of these, the second stage would model the choice among the three alternatives. A nested model is easy to estimate, given the way the survey is carried out, because the researcher knows the attributes offered to all of the households, not just the ones who chose the new alternatives.

A third aspect of this model concerns the actual estimation of benefits. This is a constructed model, in which we know the better alternatives. Hence one would think that a simple deterministic approach, based on equation (2) would give a benefit measure. The difficulty is that there is not one but three alternatives that can give a benefit estimate according to the principle of (2). The correct way of estimating benefits consistently would be to use the utility function in (12) or the version for the nested logit model. Suppose for simplicity that there are three alternatives, and the utility for each alternative is given by $U_{j}=\alpha_{j}+\beta y+\varepsilon_{j}$. Then if the $\varepsilon_{j}$ are distributed as extreme values, (12) gives the indirect utility function. Now consider the welfare measure of the value of access to alternative 1 . According to (13), it is given by ${ }^{18}$

$$
\mathrm{cv}=-\ln \left[\left\{\exp \left(\alpha_{1}\right)+\exp \left(\alpha_{2}\right)\right\} /\left\{\exp \left(\alpha_{1}\right)+\exp \left(\alpha_{2}\right)+\exp \left(\alpha_{3}\right)\right\}\right] / \beta
$$

Note that this welfare measure is not pairwise--it simply measures the expected maximum utility for alternative 1 when the three alternatives are available, irrespective of the base case. If the individual is in alternative 1 , and we would like to know the willingness to pay for 2 versus 1 , then 
we would compute the amount of money that would make the person indifferent between 1 and 2, given that we know that 3 is not a choice. This would be

$$
\mathrm{cv}=-\ln \left(\left(\exp \left(\alpha_{1}\right)\right) /\left(\exp \left(\alpha_{1}\right)+\exp \left(\alpha_{2}\right)\right) / \beta\right. \text {. }
$$

Note that this is completely symmetric--the cv for 2 given the choice of 1 or 2 is just the negative of the $\mathrm{cv}$ for 1 given 1 and 2 in the choice set.

A related method, conjoint analysis, which was developed from marketing studies, has a respondent rank a set of scenarios, each with a variety of attributes. Conjoint analysis was developed as a tool for marketing and transportation studies and has some promise for evaluating multiple attributes in project analysis. See for example Opaluch et al.and Louviere ${ }^{19}$.

\section{CONCLuSiOnS.}

The intent of this paper is to provide a context for the estimation of benefits as part of project analysis. It has reviewed recent developments in non-market valuation, including contingent valuation, hedonic models and random utility models. The circumstances for project analysis are quite different from the typical settings for non-market valuation, where the majority of the studies are undertaken in academic settings or in conjunction with legal suits and damage assessment. The challenge for project analysis is to take advantage of the developments in techniques, especially those that improve the efficiency of the methods.

The credibility of project analysis can be strengthened by several procedures. One is to document the study, both in terms of the final results and in the path taken. The nature of the documentation varies, depending on whether the analysis uses contingent valuation, hedonic models or another approach but the end result would allow an outsider to see and understand the development and culmination of the study. A second procedure is to act on the results of the benefit estimation. If the estimation results are especially fragile, and show no way of demonstrating the benefits of a project, the analysis should reveal this, and not make unwarranted claims. More important, project analysis should report negative results when they appear.

As part of the process of enhancing the credibility of project analysis, encouraging research in this area would help considerably. There are ways in which benefit analysis for projects in developing countries is quite different from circumstances in the U.S. An important issue concerns the temporal aspect. When incomes are low, credit markets poorly organized and inflation high, trade-offs between the present and the future are made quite differently and the exact nature of a contingent choice harder to understand. 
Another step would be the collecting and archiving of datasets and related questionnaires from various projects. This would not only help in assessing the specific project analysis, but would enhance the long run ability to do project analysis. It would also permit the study of benefit transfers, by having data on similar projects but different countries. 


\section{REFERENCES.}

Adamovicz, W., J. Louviere, and M. Williams. 1994. Combining revealed and stated preference methods for valuing environmental amenities. Journal of Environmental Economics and Management. 26: 271-292.

Alberini, A. and R. Carson. 1994. Choice of threshholds for efficient binary discrete choice estimation. Working paper. University of California, San Diego.

Ardila, S. 1993. Guia para la utilizacion de modelos econometricos en aplicaciones del metodo de valoracion contingente. Documento de Trabajo ENP101. Banco Interamericano De Desarrollo.

Arguea, N. and C. Hsiao. 1993. Econometric issues of estimating hedonic price functions. Journal of Econometrics. 60: 246-267.

Amemiya, T. 1985. Advanced econometrics. Cambridge Mass.: Harvard University Press.

Arrow K., R.Solow, P. Portney, E. Leamer, R. Radner and H. Schuman. 1993. Report of the NOAA Panel on Contingent Valuation. U.S. Department of Commerce.

Bartik, T. 1987. The estimation of demand parameters in hedonic price models. Journal of Political Economy. 95:81-88.

Bartik, T.J. 1988. Measuring the benefits of amenities in hedonic price models. Land Economics. 64:172-183.

Bartik, T.J. and V.K. Smith. 1987. Urban amenities and public policy. In Handbook of regional and urban economics. ed. E.S. Mills. Amsterdam: North Holland Publishers.

Belsley, D.A., E. Kuh and R.E. Welch. 1980. Regression diagnostics. New York: John Wiley and Sons.

Ben-Akiva, M. and S. Lerman. 1985. Discrete choice analysis: theory and applications to travel demand. Cambridge, Mass.: MIT Press.

Bishop, R.C., and T.A. Heberlein. 1979. Measuring values of extra-market goods: are indirect measures biased? American Journal of Agricultural Economics 61:926-930.

Bockstael, N.E., and K.E. McConnell. 1993. Public goods as characteristics of non-market commodities. Economic Journal 103:1244-1257.

Bockstael, N.E., K.E. McConnell and I.E. Strand. 1988. Benefits from improvements in Chesapeake Bay water quality. Report prepared for US Environmental Protection Agency, Cooperative Agreement CR-811043-01-0. College Park, MD: University of Maryland.

Braden, J.B. and C. Kolstad (eds.). 1991. Measuring the demand for environmental quality. New York: North Holland Publishers. 
Cameron, T.A. 1988. A new paradigm for valuing non-market goods using referendum data. Journal of Environmental Economics and Management. 15:355-379.

Cameron, T.A., and M. James. 1987. Efficient estimation methods for "closed-end" contingent valuation surveys. Review of Economics and Statistics 69:269-276.

Carrizosa, Santiago. 1993. Transferencia de beneficios ambientales en latinoamerica. Unpublished. Banco Interamericano de Desarrollo.

Carson, R.C. 1991. Constructed markets. In Measuring the demand for environmental quality. ed. Braden and Kolstad. New York: Elsevier Science Publishers.

Carson, R.T., W.M. Hanemann, R.J. Kopp, J.A. Krosnick, R.C. Mitchell, S. Presser, P.A. Ruud, and V.K. Smith. 1994a. Prospective Interim Lost Use Value Due to DDT and PCB Contamination in the Southern California Bight. NOAA contract no. -DGNC-1-00007

Carson, R.T., L. Wilks, and D. Imber. 1994b. Valuing the preservation of Australia's Kakadu Conservation Zone." Oxford Economic Papers.46:727-749.

Cooper, J. 1993. Optimal bid design for dichotomous choice contingent valuation surveys. Journal of Environmental Economics and Management. 24: 25-40.

Cooper, J. and J. Loomis. 1992. Sensitivity of willingness to pay estimates to bid design in dichotomous discrete choice contingent valuation models. Land Economics. 68: 211-224.

Cropper, M. L., L. Deck and K. E. McConnell. 1988. On the choice of functional form for hedonic price equations. Review of Economics and Statistics, 70:668-675.

Cropper, M.L., L. Deck, N. Kishor and K.E. McConnell. 1993. Estimating the value of environmental amenities from single market data. Review of Economics and Statistics. 75: 225-232.

Diamond, P. and J. Hausman. 1994. Contingent valuation: is some number better than no number? Journal of Economic Perspectives. 8: 45-64.

Domencich, T., and D. McFadden. 1975. Urban travel demand: a behavioral analysis. Amsterdam: North-Holland.

Duffield, J. and D. Patterson. 1991. Inference and optimal design for a welfare measure in dichotomous choice contingent valuation. Land Economics. 67:225-239.

Eom ,Y.S. and Smith, V.K. 1994. Calibrated nonmarket valuation. unpublished paper.

Epple, D. 1987. Hedonic prices and implicit markets: estimating demand and supply functions for differentiated products. Journal of Political Economy. 95:59-80.

Feather, D. 1993. Sampling and aggregation issues in random utility model estimation. American Journal of Agricultural Economics. 76: 772-780. 
Figueroa, E. (for Research Chile). 1992. Determinacion hedonica del precio de la vivienda en Paraquay. Santiago: Unpublished report.

Freeman, A.M., III. 1993 The measurement of environmental and resource values: theory and practice. Baltimore: Resources for the Future.

Greene, W. 1994. Accounting for excess zeros and sample selection in poisson and negative binomial regression models. unpublished paper. EC-94-10.

Haab, T. and K.E. McConnell. 1994. The problem of zeros in the demand for recreation. unpublished paper.

Haab, T. and K.E. McConnell. 1995. Referendum models and negative willingness to pay: alternative solutions. unpublished paper.

Hanemann, W. M. 1982. Applied welfare analysis with qualitative response models. California Agricultural Experiment Station working paper no. 241.

. 1984. Welfare evaluations in contingent valuation experiments with discrete responses. American Journal of Agricultural Economics 66:332-341.

. 1989. Welfare evaluations in contingent valuation experiments with discrete responses: reply. American Journal of Agricultural Economics 71: 1057-1061.

- 1994. Valuing the environment through contingent valuation. Journal of Economic Perspectives. 8: 19-43.

Hanemann, W. J. Loomis, and B. Kanenin. 1991. Statistical efficiency of double-bounded dichotomous discrete choice contingent valuation. American Journal of Agricultural Economics. 73:1255-1263.

Hausman, J. and D. McFadden. 1984. A specification test for multinomial logit model. Econometrica. 52: 1219-1240.

Hoehn, J., M.Berger and G. Blomquist. 1987. A hedonic model of interregional wages, rents and amenity values. Journal of Regional Science. 27:605-620.

Inter-American Development Bank. 1992. Tiete River Decontamination Stage I-Basic Sanitation Loan Proposal (BR-0190) and Accompanying Documents, including questionnaire.

. 1992. Draft Technical Appendix for Loan Document. Basic Sanitation for Fortaleza (BR-0186) and Accompanying Documents.

Johansson, P. B. Kristrom and K.G. Maler. 1989. Welfare evaluations in contingent valuation experiments with discrete response data: comment. American Journal of Agricultural Economics. 71: 104-106.

Kahneman, D. and J. Knetsch. 1992. Valuing public goods: the purchase of moral satisfaction. Journal of Environmental Economics and Management. 22:57-70. 
Kanemoto, Y. 1988. Hedonic prices and the benefits of public projects. Econometrica. 56: 981989.

Kanenin, B. 1993. Optimal experimental design for double-bounded dichotomous choice contingent valuation. Land Economics. 69: 138-146.

Kopp, R.J. and V. K. Smith (eds.). 1993. Valuing natural assets. Baltimore: Resources for the Future.

Kristrom, B. 1990. A non-parametric approach to the estimation of welfare measures in discrete response valuation studies. Land Economics. 66:135-139.

Larson, D., J. Loomis, Y.-L. Chien 1993. Combining behavioral and conversational approaches to value amenties. paper presented at AERE session, Orlando, Florida.

Loomis, J., A. Gonzalez-Caban and R. Gregory. 1994. Substitutes and budget constraints in contingent valuation, Land Economics 70:499-506.

Louviere, J.J. 1988. Conjoint analysis modelling of stated preferences. Journal of Transport Economics and Policy. 10: 93-119.

Maddala, G.S. 1983. Limited dependent and qualitative variables in econometrics. New York: Cambridge University Press.

Maler, K.G. 1974. Environmental economics: a theoretical inquiry. Baltimore: Johns Hopkins University Press Resources for the Future.

McConnell, K.E. 1984. Identification of Preference Parameters in Hedonic Models. report to EPA.

1990. Models for referendum data. Journal of Environmental Economics and Management.18:19-34.

1994. Consumer surplus for discrete choice models. Working paper. University of Maryland.

McConnell, K.E. and J. Ducci. 1989. Valuing environmental amenities in developing countries: two case studies. paper presented at ASSA annual meetings, Atlanta, Ga.

McFadden, D. 1974. Conditional logit analysis of qualitative choice behavior. In Frontiers in econometrics, ed. P. Zarembka. New York: Academic Press.

1978. Modelling the choice of residential location. In Spatial interaction theory and planning models, eds. Karlquist, Lundquist, Snickars, and Weibull. New York: North-Holland Publishing Company.

1994. Contingent valuation and social choice. American Journal of Agricultural Economics. 76:689-708. 
Michaels, R.G. and V.K. Smith. 1990. Segmentation and valuing amenities with hedonic models. Journal of Urban Economics. 28:223-42.

Mitchell, R.C., and R. Carson. 1989 Using surveys to value public goods: the contingent valuation method. Washington: Resources for the Future.

Morey, E. 1994. Two rums uncloaked: nested-logit models of site choice and nested-logit models of participation and site choice. paper presented at 1994 W133 meetings, Tucson, Ariz.

Niklitschek, M. and J. Leon. 1994. Combining intended demand and yes/no responses in the estimation of contingent valuation models. Inter-American Development Bank. unpublished.

Nyquist, H. 1992. Optimal designs of discrete response experiments in contingent valuation studies. Review of Economics and Statistics.74:559-563.

Opaluch, J.J., S Swallow, T. Weaver, C. Wessells, and D. Wichelns. 1993. Evaluating impacts from noxious facilities. Journal of Environmental Economics and Management. 24: 4159.

Palmquist, R.B. 1991. Hedonic methods. In Measuring the demand for environmental quality. ed. Braden and Kolstad. New York: Elsevier Science Publishers.

Parsons, G. 1986. An almost ideal demand system for housing attributes. Southern Economic Journal 53:347-363.

Parsons, G. and M. Kealy. 1992. Randomly drawn opportunity sets in a random utility model. Land Economics. 68: 93-106.

Parsons, G. and M Needelman. 1992. Site aggregation in a random utility model of recreation. Land Economics. 68: 418-433.

Research Chile. 1991. Investigacion de disposicion a pagar por soluciones de vivienda progresiva. Santiago: Unpublished report.

Randles, R. and D Wolfe. 1979. Introduction to the theory of nonparametric statistics. New York: John Wiley and Sons.

Roback, J. 1982. Wages, rents, and the quality of life. Journal of Political Economy. 90:12571258 .

Rohatgi, V.K. 1976. An introduction to probability theory and mathematical statistics. New York: John Wiley.

Small, K.A., and H.S. Rosen. 1981. Applied welfare economics with discrete choice models. Econometrica 49:105-130.

Smith, V.K. 1992. Arbitrary values, good causes and premature verdicts. Journal of Environmental Economics and Management. 22: 71-89. 
Turnbull, B. 1976. The empirical distribution function with arbitrarily grouped, censored and truncated data. Journal of the Royal Statistical Society, Series B. 38:290-295.

\section{ENDNOTES}

${ }^{1}$ It is impossible in the space of a paper like this to give a complete bibliography. Even limited to contingent valuation, the entries numbered more than a 1000 in 1992. While the other areas covered, random utility models and hedonic prices, and not currently as topical, they too would warrant an extensive bibliography. Richard Carson and associates occasionally document the contingent valuation literature.

${ }^{2}$ The choke price here need not be given by the market. It may be an implicit price which reflects the effort that the household must put out to obtain the service. For example, consider a household which can purchase water periodically from a vendor or retrieve water from a river. Each of the sources is a different commodity, and each has a choke price which depends on the characteristics and ease of obtaining the other source.

${ }^{3}$ This overestimation stems from the index number problem that results from using pre-investment price changes. Because the Kanemoto results allows complete adjustment, it is different from the static result which shows that the bid function is more concave than the hedonic price function, and therefore the area under the hedonic price function is greater than the area under the bid function, implying that the hedonic price function overestimates the true benefits, which would be the area under the bid function. The latter point is developed in McConnell, 1984. See also the discussion in Bartik 1988 and Palmquist.

${ }^{4}$ That is, cv satisfies

$$
\alpha \mathrm{q} * \beta(\mathrm{y}-\mathrm{cv})+\varepsilon_{1}=\alpha \mathrm{q}^{0}+\beta \mathrm{y}+\varepsilon_{0}
$$

Solving for cv yields

$$
\mathrm{cv}=\left(\alpha\left(\mathrm{q} * \mathrm{q}^{0}\right)+\varepsilon_{0}-\varepsilon_{1}\right) / \beta .
$$

Taking the expectations gives (10), because the errors, $\mathrm{e}_{1}$ and $\mathrm{e}_{0}$, are assumed to be mean zero.

${ }^{5}$ For the extreme value variate $\varepsilon$, the density $\mathrm{f}(\varepsilon)=\exp (-\varepsilon-\exp (-\varepsilon))$. From $(11), \mathrm{v}_{\mathrm{i}}=\mathrm{u}_{\mathrm{i}}+\varepsilon_{\mathrm{i}}\left(\mathrm{u}_{\mathrm{i}}=\alpha_{\mathrm{i}}+\beta\left(\mathrm{y}-\mathrm{p}_{\mathrm{i}}\right)\right)$ and $v_{i}$ is also extreme value. The expected value of the maximum of $v_{i}$ is the expected value of the nth order statistic: $E\left(v_{i} \mid v_{i}>v_{j}, j\right.$ different from $\left.i\right)=\ln \left[\sum_{i=1}^{m} \exp \left(\alpha_{i}+\beta\left(y-p_{i}\right)\right)\right]+k$. For a discussion of order statistics, see Randles and Wolfe, chapter 1.

${ }^{6}$ This can be derived by noting that we can write the term $\ln \left[\sum_{\mathrm{i}=1}^{\mathrm{m}} \exp \left(\alpha_{\mathrm{i}}+\beta\left(\mathrm{y}-\mathrm{p}_{\mathrm{i}}\right)\right)\right]$ as $\ln \exp (\mathrm{y})+$ $\ln \left[\sum_{\mathrm{i}=1}^{\mathrm{m}} \exp \left(\alpha_{\mathrm{i}}-\beta\left(\mathrm{p}_{\mathrm{i}}\right)\right)\right]$ so that $\ln \exp (\mathrm{y})$ can be subtracted from both sides of the welfare measure and 
hence disappears. We can also factor cv from all the terms on the right hand side of this expression. This leads to the result in the text.

7 Expression (14) comes from the expression for the probability of choosing alternative 1, which is given by

$\operatorname{Prob}(1)=\exp \left(\alpha_{1}+\beta\left(y-p_{1}\right)\right) / \sum_{j=1}^{m} \exp \left(\alpha_{j}-\beta\left(y-p_{j}\right)\right.$ so that 1-Prob(1) is inside the brackets of equation (13).

${ }^{8}$ Amemiya, chapter 9, derives the choice probabilities from the generalized extreme value distribution. McFadden has shown that for this model to be consistent with stochastic utility maximization, $\theta$ must lie in the unit interval.

${ }^{9}$ The probability is given by

$\operatorname{Prob}(\mathrm{s})=\left\{\sum_{\mathrm{k}=1}^{\mathrm{n}_{\mathrm{s}}} \exp \left(\alpha \mathrm{q}_{\mathrm{ks}}+\beta\left(\mathrm{y}-\mathrm{p}_{\mathrm{ks}}\right)\right\}^{\theta} / \sum_{\mathrm{m}=1}^{\mathrm{s}}\left\{\sum_{\mathrm{j}=1}^{\mathrm{n}_{\mathrm{s}}} \exp \left(\alpha \mathrm{q}_{\mathrm{mj}}+\beta\left(\mathrm{y}-\mathrm{p}_{\mathrm{jm}}\right)\right\}^{\theta}\right.\right.$. Note that $\exp \left(\alpha_{\mathrm{k}} \mathrm{q}_{\mathrm{ks}}+\beta\left(\mathrm{y}-\mathrm{p}_{\mathrm{ks}}\right)=\exp (\beta \mathrm{y}) \exp \left(\alpha_{\mathrm{k}} \mathrm{q}_{\mathrm{ks}}-\beta \mathrm{p}_{\mathrm{ks}}\right)\right.$. This term, $\exp (\beta \mathrm{y})$, can be factored from the numerator and the denominator and hence will cancel out.

${ }^{10}$ It is worth drawing out the benefit measures for multiple quality changes. This shows the importance of complementarity or substitutability and it helps in dealing with the imbedding problem in contingent valuation. Writing out the more general expression for the benefit measure for quality changes explicitly would give

$$
\mathrm{V}\left(\mathrm{p}, \mathrm{q}_{1}^{*}, \mathrm{q}_{2}^{*}, \mathrm{y}-\mathrm{cv}_{\mathrm{q}}\right)=\mathrm{V}\left(\mathrm{p}, \mathrm{q}_{1}^{0}, \mathrm{q}_{2}^{0}, \mathrm{y}\right) \text {. }
$$

The q's could be connected in a service flow sense, such as pathogens and suspended solids in a liter of drinking water, or they could be connected in a technical supply sense, such as sewerage and drainage control but not as part of the service flow.

To make this model concrete, let $\mathrm{q}_{1}$ stand for drainage and $\mathrm{q}_{2}$ stand for sewer hookup. Then $\mathrm{cv}_{\mathrm{q}}$ can be written:

(b) $\quad \mathrm{cv}_{\mathrm{q}}$ (drainage, hookup $\mid$ neither $)=$

(change in utility due to drainage and hookup / given no drainage and no hookup)/mu

where $\mathrm{mu}_{\mathrm{y}}$ stands for marginal utility of income and dividing the change in utility by the marginal utility of income converts utility to income. Hence this is just the monetized increase in utility from gaining better drainage and a hookup to a sewer. Now suppose that the researcher asks for the willingness to pay for better drainage only. Then the willingness to pay is

(c) $\quad \mathrm{cv}_{\mathrm{q}}($ drainage $\mid$ neither $)=$

(change in utility due to drainage $/$ given no drainage and no hookup)/ $/ \mathrm{mu}_{\mathrm{y}}$;

And then the willingness to pay for hookup only:

$$
\left.\mathrm{cv}_{\mathrm{q}} \text { (hookup } \mid \text { neither }\right)=
$$

(change in utility due to hookup | given no drainage and no hookup)/mu $\mathrm{m}_{\mathrm{y}}$.

The sum of (c) and (d) is greater than (b) if drainage and hookup are complementary, and less if drainage and hookup are substitutes. Whether they are complements or substitutes depends on the utility function and the budget constraint. In utility sense, goods are complementary if more of one good increases the marginal utility of the other good. The budget implies less income to spend on the second service, given that the first service has been purchased, which means a higher marginal utility of income. Hence a tighter budget induces substitutability between goods but may not offset the complementarity in a utility sense. 
This problem is related to but different from the embedding problem which has become a prominent issue in contingent valuation based on the criticism of Kahnemann and Knetsch. The embedding problem relates $\mathrm{cv}_{\mathrm{q}}$ (hookup $\mid$ neither) $+\mathrm{cv}_{\mathrm{q}}\left(\right.$ drainage $\mid$ hookup) to $\mathrm{cv}_{\mathrm{q}}$ (drainage, hookup $\mid$ neither). See also the paper by V.K. Smith.

${ }^{11}$ The original stated "Uma maneira de pagar pelas obras seria atraves de um tarifa mensal que seria reajustada de acordo com a inflacao", from the IDB loan document for Fortaleza.

${ }^{12}$ The original read "Que se construa o coletor tronco, retirando o esgoto do corrego pagar CB $\$ X$ por mes, reajustado". This is from the IDB loan document which included the questionnaire.

${ }^{13}$ The problem is related to the question of whether the observed zeroes are true zeroes. That is, when someone says no to a CV question, is there any price at which a yes would be induced, or is the respondent simply not interested in the service at any price? In this regard, see the papers by Greene and Haab and McConnell.

${ }^{14}$ That is, in a probit model of the form $\mathrm{y}=\mathrm{x} \beta+\varepsilon$, where $\varepsilon$ is distributed $\mathrm{N}\left(0, \sigma^{2}\right)$, the estimation gives only the normalized parameters $\beta / \sigma$, essentially because scale is not observed in a discrete choice model.

${ }^{15}$ One could also use the mean, which comes from the expectation $\operatorname{Eexp}((\alpha+\gamma s) \varepsilon)$ which is given by $\exp \left(\alpha+\gamma s+\sigma^{2} / 2\right)$ for the lognormal variable $\varepsilon$.

${ }^{16}$ Michaels and Smith demonstrate the effects of not segmenting markets which seem to be different by observers of the markets.

${ }^{17}$ See also the paper by Roback and the more general discussion in Freeman, chapter 12.

${ }^{18}$ In (13), we take the sum of the exponents of utility over all alternatives, then take the same sum without the alternative being evaluated, form the ratio and take the log. In the following expression in the text, we invert the ratio and take the negative of the log, resulting in the same calculation.

${ }^{19}$ Perhaps the most significant developments in contingent valuation have come from changes in the nature of questioning. These changes are reflected in the names given to the CV process: stylized conversations or constructed preferences or stated preferences. These processes require considerable questionnaire development and well trained interviewers and cannot be replicated in most cases of project analysis. 